\title{
A Newly Generated DOCK8-expressing T Follicular Helper Cell Type, aiCD4 T Cell, Causes Systemic Lupus Erythematosus: Self-Organized Criticality Theory
}

Shunichi Shiozawa ( $\nabla$ shiozawa@port.kobe-u.ac.jp)

Institute for Rheumatic Diseases

Ken Tsumiyama

Institute for Rheumatic Diseases

Keiichi Sakurai

Institute for Rheumatic Diseases

Takahiko Horiuchi

Kyushu University Beppu Hospital

Tsukasa Matsubara

Matsubara Mayflower Hospital

Motohiro Oribe

Oribe Clinic

Takashi Yamane

Kakogawa City Hospital

Hidetoshi Kagawa

Himeji Red Cross Hospital

Quan-Zhen Li

University of Texas Southwestern Medical Center

Yohei Mukai

Kan Institute

Masaaki Miyazawa

Kinki University School of Medicine

Biological Sciences - Article

Keywords: Autoimmune Disease, Autoantibodies, TCR Repertoires

Posted Date: October 1st, 2020

DOI: https://doi.org/10.21203/rs.3.rs-82784/v1 
License: (c) (i) This work is licensed under a Creative Commons Attribution 4.0 International License. Read Full License 
1 A Newly Generated DOCK8-expressing T Follicular Helper Cell Type, aiCD4 T Cell,

2 Causes Systemic Lupus Erythematosus: Self-Organized Criticality Theory

3

4 Shunichi Shiozawa, ${ }^{1,2,3,4 *}$ Ken Tsumiyama, ${ }^{1,2,3}$ Yumi Miyazaki, ${ }^{2,3}$ Kenichi Uto, ${ }^{3}$ Keiichi

5 Sakurai, ${ }^{1,2}$ Toshie Nakashima, ${ }^{3}$ Hiroko Matsuyama, ${ }^{3}$ Chisako Satonaka, ${ }^{3}$ Ai Doi, ${ }^{3}$ Yaho

6 Nishikawa, ${ }^{3}$ Manabu Izumikawa, ${ }^{3}$ Yuko Fujita, ${ }^{3}$ Mai Takimoto, ${ }^{3}$ Takahiko Horiuchi, ${ }^{2}$

7 Tsukasa Matsubara, ${ }^{4}$ Motohiro Oribe, ${ }^{5}$ Takashi Yamane, ${ }^{6}$ Hidetoshi Kagawa, ${ }^{7}$ Quan-

8 Zhen Li, ${ }^{8}$ Keiko Mizuno, ${ }^{9}$ Yohei Mukai, ${ }^{9}$ Kazuhiro Murakami, ${ }^{10}$ Takuji Enya, $,{ }^{11}, 12$ Shota

9 Tsukimoto, ${ }^{11,13}$ Yoshiyuki Hakata, ${ }^{11}$ Masaaki Miyazawa, ${ }^{11,14}$ and Kazuko Shiozawa ${ }^{15}$

$11{ }^{1}$ Institute for Rheumatic Diseases, 944-25 Fujita, Katoshi 673-1462, Japan

$12{ }^{2}$ Department of Medicine, Kyushu University Beppu Hospital, 4546 Tsurumihara, Beppu 13 874-0838, Japan

$14{ }^{3}$ Division of Bioregulation, Kobe University Graduate School of Health Sciences, spital, 7-10-2 Tomogaoka, Sumaku, Kobe 654-0142, Japan

$16{ }^{4}$ Department of Medicine, Rheumatology and Orthopedic Surgery, Matsubara Mayflower 17 Hospital, 944-25 Fujita, Katoshi 673-1462, Japan

$18{ }^{5}$ Oribe Clinic, 1-8-15 Higashi-Odori, Oita 870-0823, Japan 
${ }^{6}$ Department of Rheumatology, Kakogawa City Hospital, 439 Honmachi, Kakogawa 6758611, Japan

${ }^{7}$ Department of Medicine, Red Cross Society Himeji Hospital, 1-12-1 Shimoteno, Himeji 670-8540, Japan

${ }^{8}$ Department of Immunology, University of Texas Southwestern Medical Center, 6001 Forest Park Rd/ND 6.504, Dallas, Tx75390-8814, U.S.A.

${ }^{9}$ Drug Discovery Platform, KAN Research Institute, Inc., 6-8-2 Minatojimaminamicho, 26 Kobe 650-0047, Japan.

10 Tohoku Medical and Pharmaceutical University, 4-4-1 Komatsujima, Aobaku 9818558, Japan.

${ }^{11}$ Department of Immunology, Kindai University Faculty of Medicine, 377-2 Ohno-

30 Higashi, Osaka-Sayama, Osaka 589-8511, Japan.

${ }^{12}$ Department of Pediatrics, Kindai University Faculty of Medicine, 377-2 Ohno-Higashi, Osaka-Sayama, Osaka 589-8511, Japan.

${ }^{13}$ Department of Anesthesiology, Kindai University Faculty of Medicine, 377-2 Ohno-

Higashi, Osaka-Sayama, Osaka 589-8511, Japan.

${ }^{14}$ Kindai University Anti-Aging Center, 3-4-1 Kowakae, Higashi-Osaka, Osaka 577-8502, Japan. 
$37 \quad{ }^{15}$ Rheumatology and Collagen Disease Center, Hyogo Prefectural Kakogawa Medical

38 Center, 203 Kanno, Kakogawa 675-8555, Japan

39

40 Correspondence: shiozawa@port.kobe-u.ac.jp

41 
Systemic lupus erythematosus (SLE) is a prototypical autoimmune disease of unknown

cause. We show here that a novel $\mathrm{T}$ follicular helper cell type expressing the guanine nucleotide exchange factor DOCK8 on the cell surface causes SLE. These cells, which we have designated autoantibody-inducing CD4 T (aiCD4 T) cells, are generated after resuscitation from anergy following strong TCR stimulation by antigen. When mice normally not prone to autoimmune disease were repeatedly immunized with an antigen such as OVA, they generated DOCK $8^{+} \mathrm{CD} 4 \mathrm{~T}$ cells. These DOCK $8^{+} \mathrm{CD} 4 \mathrm{~T}$ cells, in vivo and also upon transfer to naïve mice, induced a variety of autoantibodies and lesions characteristic of SLE. TCR repertoire analyses showed that a substantial number of novel TCR repertoires were generated in the DOCK $8^{+} \mathrm{CD} 4 \mathrm{~T}$ cells, which induced novel autoantibodies upon transfer to naïve mice. $\mathrm{DOCK} 8^{+} \mathrm{CD} 4 \mathrm{~T}$ cells are localized in splenic red pulp, the space immunoreactive against a variety of antigens, and specifically increased in the peripheral blood of SLE patients in association with disease activity. AntiDOCK 8 antibody treatment ameliorated the lesions induced by DOCK $8^{+} \mathrm{CD} 4 \mathrm{~T}$ cells and in lupus model (NZB x W) F1 mice. Thus, when CD4 T cells are overstimulated by an external disturbance, i.e., repeatedly stimulated with antigen, to levels that surpass the system's self-organized criticality, these cells express DOCK8 on the cell surface and 
60 acquire autoreactivity via TCR re-revision at the periphery. These DOCK $8^{+} \mathrm{CD} 4 \mathrm{~T}$ cells

61 subsequently induce a variety of autoantibodies and SLE. 
Systemic lupus erythematosus (SLE) is a classical systemic autoimmune disease

64 characterized by fever, organ pathologies such as erythematous skin rash or lupus nephritis, and the generation of a variety of autoantibodies including anti-double stranded DNA (anti-dsDNA) Ab. Although SLE has long been suspected to be caused by some type of autoimmune responses, the details of its etiology have remained elusive. Interferon $\alpha$ (IFN $\alpha$ ) has been proposed to be a principal driver of SLE (1-16), however, it has also been reported that IFN $\alpha$ can sometimes be protective against SLE $(17,18)$, IFN $\alpha$ treatment itself does not induce anti-Sm Ab, which is considered diagnostic of SLE $(1,16,19,20)$, and monoclonal anti-IFNa Ab therapy is only modestly effective in treating SLE (21-23). induce autoimmune disease in mice normally not prone to such diseases by repeated stimulation with an antigen. This repeated stimulation leads to the generation of a novel type of CD4 T cell, which we designate aiCD4 T cell (autoantibody-inducing CD4 T cell), capable of directing the production of a variety of autoantibodies. We have proposed that the induction of aiCD4 $\mathrm{T}$ cells is due to overstimulation of CD4 $\mathrm{T}$ cells to levels that exceed the immune system's "self-organized criticality" (24). The aiCD4 T cells thus 
generated subsequently overstimulate $\mathrm{CD} 8^{+} \mathrm{T}$ cells, driving them to become cytotoxic $\mathrm{T}$

81 lymphocytes (CTL) via antigen cross-presentation $(24,25)$, and this ultimately results in

82 the development of SLE. Thus, SLE is induced not by an autoimmune response, but by

83 the expansion of aiCD4 $\mathrm{T}$ cells having de novo autoreactivity. The key player in this

84 pathogenesis is the aiCD4 $\mathrm{T}$ cell, and in the present study, we have tried to clarify the

85 nature of these cells. The contribution of aiCD4 T cells to the pathogenesis of SLE was

86 investigated by cell transfer studies in mice and by quantification of aiCD4 T cells in the

87 peripheral blood and tissue of patients diagnosed with SLE. We also investigated a

88 potential therapy for SLE using an antibody directed against these cells.

\section{Identification of $\mathrm{DOCK8}^{+} \mathrm{CD} 4 \mathrm{~T}$ cell as aiCD4 $\mathrm{T}$ cell that induces SLE}

91 To isolate and characterize aiCD4 T cells, we first induced the aiCD4 T cells in BALB/c

92 mice by $12 x$ repeated intraperitoneal (i.p.) immunization with OVA without adjuvants.

93 Next, various subsets of splenic CD4 T cells were taken and transferred to naïve recipient

94 mice. For each subset we assessed the generation of rheumatoid factor (RF) and anti-

$95 \mathrm{dsDNA} \mathrm{Ab}$ in the recipient mice and further found that these autoantibodies could be

96 induced by transferring the $\mathrm{CD} 45 \mathrm{RB}^{\text {lo }} \mathrm{CD} 122^{\text {lo }} \mathrm{PD}-1^{+} \mathrm{CD} 4 \mathrm{~T}$ cell subset (Extended Data

97 Fig. 1a). The membrane and cytosolic fractions were extracted from these cells, and 
subjected to electrophoresis and silver staining. Protein bands differentially expressed were then excised and analyzed by in-gel digestion followed by mass spectrometry. We

100 found that the guanine nucleotide exchange factor DOCK8 was uniquely expressed in the membrane fraction of this $\mathrm{T}$ cell subset (Fig. 1a). In mice repeatedly immunized with

102 OVA, the number of DOCK $8^{+}$CD4 T cells gradually increased in the spleen up to the

103 final 12x immunization (Fig.1b). We then isolated DOCK $8^{+} \mathrm{CD} 4 \mathrm{~T}$ cells from these OVA-

104 immunized mice and transferred them to naïve recipient mice. The recipient mice

105 generated RF and anti-dsDNA Ab and developed renal disease (Extended Data Figs. 2a,

106 2b). To more closely examine the role of the transferred DOCK $8^{+} \mathrm{CD} 4 \mathrm{~T}$ cells in the 107 development of renal disease, we immunized BALB/c mice $8 \mathrm{x}$ with OVA. At this time 108 point, nephritis-inducing CTLs had yet to mature. We then treated naive mice with anti$109 \mathrm{CD} 4 \mathrm{Ab}$ to deplete their CD4 T cells and transferred into them, the DOCK8 ${ }^{+} \mathrm{CD} 4 \mathrm{~T}$ cells 110 isolated from the spleens of the BALB/c mice immunized 12x with OVA. The recipients 111 developed autoantibodies and renal disease characteristic of WHO class IV and V (26)

112 advanced disease (Figs. 1c, 1d). This indicates that DOCK $8^{+} \mathrm{CD} 4 \mathrm{~T}$ cells are required for

113 the induction of autoantibodies and renal disease in this mouse model. In addition to

114 kidney disease similar to SLE, transfer of $\mathrm{DOCK}^{+} \mathrm{CD} 4 \mathrm{~T}$ cells into naïve mice also 115 induced dermatitis often accompanied by dermal perineuritis in 4 out of 5 recipient mice, 
116 but none in mice receiving control DOCK8 ${ }^{-}$CD4 T cells (Fig. 1e. 1f; $p=0.0476$ by Fisher's

117 exact test). Panniculitis in the dermis and skin epidermal liquefaction degeneration,

118 classical lesion of SLE, were observed in 2 of 5 DOCK $8^{+}$CD4 T recipients, and none in

119 the control mice (Fig. 1e). Lung interstitial pneumonitis was seen in 4 of 5 DOCK 8 CD4

120 T recipients, and 1 of 5 control mice (Fig. 1f, $1 \mathrm{~g}$ ). Pericholangitis with liver cell necrosis

121 was seen in 2 of 5 DOCK $8^{+} \mathrm{CD} 4 \mathrm{~T}$ recipients, and none in the control (Fig. 1f, 1g). Diffuse

122 thyroiditis was seen in 2 of $5 \mathrm{DOCK} 88^{+} \mathrm{CD} 4 \mathrm{~T}$ recipients, and none in the control. Splenic

123 perivascular fibrosis with amyloid-like deposition and classical onion skin lesion

124 pathognomonic of SLE (27) were seen in all 5 of $5 \mathrm{DOCK} 8^{+} \mathrm{CD} 4 \mathrm{~T}$ recipients, and none

125 in the control (Fig. 1f, $1 \mathrm{~g} ; p=0.0079$ by Fisher's exact test). Lung interstitial pneumonitis

126 seen in the DOCK $8^{+}$CD4 T recipients was often accompanied by angiitis (Fig. 1g).

127 DOCK8 ${ }^{+}$CD4 $\mathbf{T}$ cell is a novel $\mathbf{T}$ follicular helper cell, located in splenic red pulp

128 DOCK $8^{+}$CD4 T cells were labelled with Au-tagged anti-DOCK8 Ab and examined by 129 immunoelectron microscopy. These cells were observed to be relatively large 130 lymphocytes with abundant endoplasmic reticulum and mitochondria (Fig. 2a). DOCK $8^{+}$

$131 \mathrm{CD}_{4} \mathrm{~T}$ cells were $\mathrm{CD} 44^{+}, \mathrm{CD} 2 \mathrm{~L}^{-}, \mathrm{ICOS}^{+} \mathrm{PD}-1^{+} \mathrm{CXCR}^{+}, \mathrm{CD}^{+}$, and Thy $1.2^{+}$, indicative 132 of activated T follicular helper cells $(28,29)$ (Fig. 2b; Extended Data Fig.3, 4), in particular, 133 the type of long-lived germinal center (GC) effector T follicular helper cells (30,31) which 
134 also express FR4 and GL7 (Fig.2b). These cells also expressed Ly6C, LFA1, CCR4,

135 CD123, CD23 (32,33) (Fig.2b; Extended Data Fig. 3, 4a; Supplementary Table 1). The

136 DOCK $8^{+}$CD4 T cells produced higher amounts of IFN $\gamma$, IL-4, IL-6, IL-17, IL-21, and

137 IL-22 (Fig. 2c), whereas IL-12 or IFN $\alpha$ was undetectable. The CD25 ${ }^{+}$Foxp $^{+}$population

138 were not increased by $12 x$ stimulation with OVA (Extended data Fig. 4b).

139 In the patients with active SLE, DOCK $8^{+}$CD4 T cells were mainly located in splenic

140 sinus, red pulp, in a disease-specific fashion (Fig. 2d). This is, likely because they lack

141 CCR7, and also express increased CD147 and LFA1 (Fig. 2b; Extended Data Fig. 3),

142 which should prevent $\mathrm{T}$ cells entry from the vasculature into $\mathrm{T}$ zones and anchor them

143 against blood flow (34). Splenic sinus, red pulp, is a suitable location to encounter

144 circulating antigens and nurse the autoreactive B cells that derive from bone marrow or

145 shuttle between the marginal and follicular zones by expressing CD138, undergoing

146 class-switch recombination and readily differentiating into plasma cells (35-37). In the

147 spleen of 12x OVA-immunized mice, indeed, activated B cells with CD138 markers

148 classified as plasma cells and follicular B cells were significantly increased (Extended

149 Data Fig. 5). In the red pulp, DOCK $8^{+}$CD4 $\mathrm{T}$ cells could also meet the red pulp

150 macrophages which are highly efficient at cross-presenting antigens to $\mathrm{T}$ cells and

151 maturing CTLs (38) and thus important for the induction of lupus tissue injuries $(24,25)$. 


\section{Circulating DOCK8 ${ }^{+}$CD4 T cells increase in association with SLE disease activity}

153 Since $\mathrm{T}$ follicular helper cells are measurable at the periphery and their frequency reflects

154 in vivo dynamics (39), we tried to measure DOCK8 ${ }^{+}$CD4 T cells in the peripheral blood

155 of SLE patients. Higher numbers of circulating DOCK $8^{+}$CD4 T cells were found in the

156 peripheral blood of patients, and these numbers correlated with higher SLEDAI disease

157 activity scores (40) (Fig. 2e). This indicates that surface expression of DOCK8 on CD4 T

158 cells was associated with high activation levels of CD4 T cells and SLE disease activity.

159 It was noted here that although $\mathrm{DOCK} 8^{+} \mathrm{CD} 4 \mathrm{~T}$ cells were significantly decreased by

160 conventional therapy, a substantial number of patients remained with slightly increased

161 DOCK $8^{+}$CD4 T cell numbers compared with disease controls. This would be compatible

162 with the therapeutic sequellae of SLE in which the patients require tapered but continued

163 therapy with prednisolone or immunosuppressive agents for several years, suggesting that

$164 \mathrm{DOCK}^{+} \mathrm{CD} 4 \mathrm{~T}$ cells, once activated, did not disappear quickly in response to

165 conventional therapy.

166 DOCK8 ${ }^{+}$CD4 T cells induce autoimmunity, characteristic of SLE

167 In the DOCK $8^{+} \mathrm{CD} 4 \mathrm{~T}$ cells, genes encoding components of $\mathrm{V}(\mathrm{D}) \mathrm{J}$ recombinase complex,

168 recombination-activating genes 1 and 2 (RAG1/2), terminal deoxynucleotidyl transferase

169 (TdT) and surrogate TCR $\alpha$ chain (pT $\alpha$ ), were up-regulated (Fig. 3a). TCR basal signaling 


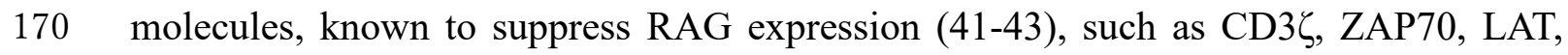

171 SLP-76, PLC $\gamma 1$, ERK, Akt, and NFAT1/2 and their nuclear translocation were down-

172 regulated (Fig. 3b), and the transcription factor GATA3 essential for RAG assembly (44-

173 46) was up-regulated (Fig. 2b).

174 TCR repertoire analyses showed that the diversity of TCR gene usage was restricted

175 and skewed in the direction of novel TCR repertoires, even though the stimulation was a

176 single antigen (OVA) (Fig. 3c; Extended Data Fig. 6, 7; Supplementary Table 2). The

177 heatmap representation of this repertoire reveals that this novel TCR gene usage, as

178 characterized by a combination of novel TRAV and TRAJ gene variations, was restricted

179 to the $\mathrm{DOCK}^{+}$CD4 $\mathrm{T}$ cells (Fig. 3c). A diversity score calculation $(47,48)$, which

180 included the inverted Simpson index, showed that the weighted arithmetic mean of the

181 proportional abundances of TCR repertoires in the $\mathrm{DOCK} 8^{+} \mathrm{CD} 4 \mathrm{~T}$ cells was

182 substantially restricted; $1.22 \sim 5.95 \%$ of the DOCK8- CD4 T cells (Extended Data Table

183 1). Unique TCR repertoires, unique sequence reads (USRs) having the combination of

$184 T R A V$ and TRAJ, and amino acid sequences of the CDR3 that had no identity with other

185 sequence reads, were dominantly found in the $\mathrm{DOCK} 8^{+} \mathrm{CD} 4 \mathrm{~T}$ cells compared to

186 DOCK8 ${ }^{-}$CD4 $\mathrm{T}$ cells from the same 12x OVA-immunized mice, or compared to CD4 T

187 cells from control mice mock-immunized with PBS (Extended Data Table 2; 
188 Supplementary Table 2). A variety of autoantibodies were induced when these DOCK $8^{+}$

189 CD4 T cells from 12x OVA-immunized mice were transferred into naïve mice (Fig. 1c,

190 3d). These findings together indicate that the DOCK $8^{+}$CD4 T cells had undergone TCR

191 re-revision at the periphery and were able to induce novel antibodies, including 192 autoantibodies.

\section{TCR gene chromatin accessibility}

194 aiCD4 T cells were generated following heavily repeated TCR stimulation with antigen,

195 which released them from their anergic state, irrespective of the antigen used or genetic

196 background, by the help of NKT cells (Extended Data Fig. 8; ref. 24). Thus, even repeated

197 challenge by Staphylococcus enterotoxin B (SEB), which cross-links TCR and MHC,

198 could induce aiCD4 T cells (Extended Data Fig.8; ref. 24). Likely due to these strong

199 stimulation, DOCK8 re-localized from its normal site in the cytoplasm to the cell

200 membrane (49-51) and the nuclear lamina (52,53) (Fig. 2a). Further, the progenitor,

201 transforming or reprogramming factors responsible for RAG modulation and

202 chromosomal accessibility (54-65) such as KLF4, KLF5, Zeb2, EBF1, PAX5, PAX6,

203 Bcll1a and its target Tcf4 were up-regulated (Fig. 3e; Supplementary Table 1). Nuclear

204 DOCK8 (65), by binding and activating cdc42 (52,53), can activate nuclear-WASP and

205 up-regulate $\mathrm{H} 3 \mathrm{~K} 4$ trimethyltransferase $(52,53)$ and thus may disrupt the association of 
206 TCR genes with nuclear lamina via actin movement, thereby enhance the chromatin

207 accessibility to transcription factor E2-2 (Tcf4) (Fig. 3e). PU.1 (Spi.1), which is normally

208 undetectable in mature T cells, was also expressed, and the genes up-regulated by PU.1

209 such as Bcl11a, Lmo2, Mef2c, Syk, Lyn and Cd300a, but not Bcll1b, were up-regulated

$210(54,56,57)$ (Fig. 3e). Cell surface expression of DOCK8 should also strengthen

211 immunological synapse formation $(50,51,65-67)$ together with LFA1 or HkRP3, WIP,

212 WASP and PtdIns-3-kinase (Fig. 2b, 3e; Extended Fig. 4; Supplementary Table 1).

213 We performed chromatin-immunoprecipitation sequencing (ChIP-seq) to map histone

214 acetylation (AcH3) and $\mathrm{H} 3 \mathrm{~K} 4$ methylation $(\mathrm{H} 3 \mathrm{~K} 4 \mathrm{me} 3)$ of the TCRB and TCRA genes in

215 the aiCD4 $\mathrm{T}$ cells generated by $8 \mathrm{x}$ stimulation with SEB. H3K4me3 was found to be

216 enriched at the TCRA J $\alpha 45, \mathrm{~J} \alpha 35, \mathrm{~J} \alpha 24, \mathrm{~J} \alpha 12, \mathrm{~J} \alpha 6$ and $\mathrm{E} \alpha$ gene segments and TCRB

217 5'D $31,5^{\prime} \mathrm{D} \beta 2$, 3'D 32 , and $\mathrm{E} \beta$ gene segments of both control PBS-treated and

218 experimental 8x SEB-stimulated $\mathrm{V} \beta 8^{+}$aiCD4 $\mathrm{T}$ cells. This result is in accordance with

219 the previous reports showing that the TCR gene recombination center is an open structure

220 (68-72) (Extended Data Fig. 9). However, in the 8x SEB-stimulated aiCD4 T cells,

$221 \mathrm{H} 3 \mathrm{~K} 4 \mathrm{me} 3$ was also found in the 5' proximal V $\alpha 1, \mathrm{~V} \alpha 16, \mathrm{~V} \alpha 17, \mathrm{~V} \alpha 21$, TEA, V $\beta 8.3, \mathrm{~V} \beta 6$,

222 and V $\beta 18$ gene segments. These findings are in line with the result of TCR repertoire

223 analysis in the $12 \mathrm{x}$ OVA-stimulated $\mathrm{DOCK}^{+}$aiCD4 $\mathrm{T}$ cells that 5 ' proximal $\mathrm{V} \alpha$ genes 
226 PCR) to detect blunt-end DNA fragments harboring a rearranged coding J $\alpha$ region flanked

227 by recombination signal sequences (RSS). We identified the rearranged intermediates

228 corresponding to TCR $\alpha$ joining region 12 (TCRAJ12) in the splenocytes of $8 \mathrm{x}$ SEB-

229 stimulated mice (Extended Data Fig. 9). Expression of the V $\alpha$ and J $\alpha$ genes distal from

230 TEA in autoimmunity were compatible with the general rules showing the stepwise and

231 coordinated proximal-to-distal progressions of $\mathrm{V} \alpha$ and $\mathrm{J} \alpha$ usage on individual TCRA

232 alleles in $\mathrm{CD}^{+} \mathrm{CD}^{+}$thymocytes (73). Thus, while we were unable to show directly the

233 contribution of transcription factor E2-2 or DOCK8 to TCR gene transactivation, the

234 results showed that some novel TCR chromatin regions, particularly distal V $\alpha$ and J genes,

235 were accessible in aiCD4 T cells.

236 Treatment of SLE in mice by anti-DOCK8 antibody

237 We treated 12x OVA-immunized mice with anti-DOCK8 Ab 24 hours before the 6x, 8x,

$23810 \mathrm{x}$ and 12x immunization with OVA, and the mice were studied 9 days after final, 12x, immunization. Anit-DOCK8 Ab-treated mice developed lower titers of RF and anti-Sm and anti-dsDNAAbs compared to control isotype Ig-treated mice (Fig. 4a). Renal disease was significantly ameliorated and almost cured as assessed by histology (Fig. 4b). Lesions 
242 of the skin (Fig. 1e panel E; Fig. 1f), lungs and thyroid were also significantly ameliorated

243 by anti-DOCK8 Ab treatment (Fig. 1f), and the thymic cortex was significantly atrophied.

244 We also treated female (NZBxNZW) F1 mice, a classical lupus model (74), with anti-

245 DOCK8 Ab every 15 to 24 weeks. Autoantibodies, RF, anti-Sm Ab and anti-dsDNA Ab,

246 and proteinuria were significantly decreased in the DOCK8 Ab-treated mice compared to

247 controls (Fig. 4c), suggesting that generation of disease in this lupus-prone mouse model

248 was mechanistically similar to that generated in antigen-stimulated BALB/c and C57BL/6

249 mice.

250 Relationship to interferon $\alpha($ IFN $\alpha)$ as a cause of SLE

251 We also observed that IFN response genes were up-regulated in DOCK $8^{+}$CD4 T cells

252 (Extended Data Fig. 10; Supplementary Table 1). Recent studies have shown that activation of enhancer-like promoter are preferentially associated with the expression of

254 housekeeping or stress-response genes by default, including IFN response genes $(75,76)$.

255 Upon chronic infection, $\mathrm{T}$ cells shift towards a $\mathrm{T}$ follicular helper phenotype and up-

256 regulate IFN signature genes $(77,78)$. Tcf4, which was up-regulated in DOCK8 ${ }^{+}$CD4 T

257 cells, is a transcription factor specific for plasmacytoid dendritic cells (pDC) that

258 promotes expression of the pDC-enriched genes such as SpiB, Irf8 and Zeb2 (79-81)

259 (Fig.3e; Extended Data Fig. 10; Supplementary Table 1). Microarray analyses show that 
260 DOCK $^{+}$CD4 $\mathrm{T}$ cells share some characteristics of pDC (Fig. 3e), however, pDC

261 numbers per se were not increased in 12x OVA-immunized mice (Extended Data Fig. 10).

262 Serum IFN $\alpha$ was also not increased in the sera of 12x OVA- or 8x SEB-stimulated mice

263 (data not shown), nor in most of the SLE patients studied (Fig. 2e). Serum IFN $\alpha$ was

264 slightly higher in 3 treated patients with SLE (indicated by $\bigcirc$ in Fig. 2e), whereas their

265 serum levels were still below the levels detectable in active SLE patients (7), as well as

266 in the mice in which we could induce SLE by the several-fold up-regulation of IFN $\alpha(16)$.

267 Two out of 3 patients with SLEDAI score of 0 and 3.5 (Fig. 2e) had been treated with

268 conventional therapy and potentially could have had higher IFNa levels at an earlier time,

269 which might have induced SLE. Overall however, serum IFNa was not increased in the

270 patients studied here, even though the disease mechanism described here should enhance

271 IFN $\alpha$ generation. Thus, while IFN $\alpha$ may induce SLE (16) in at least some patients, IFN $\alpha$

272 appears in most cases to exert a disease-modifying, but not causative, role in

273 manifestations such as erythematous skin rash, neuropsychiatric disorders or renal disease

$274(7,16)$. 


\section{CONCLUSIONS}

276 These results show that when CD4 T cells are overstimulated by an external disturbance,

277 i.e., repeated stimulation with antigen, to levels that surpass the system's self-organized

278 criticality, these CD4 $\mathrm{T}$ cells express DOCK8 on the cell surface and acquire

279 autoreactivity via TCR re-revision at the periphery. These DOCK $8^{+}$CD4 $\mathrm{T}$ cells

280 subsequently induce a variety of autoantibodies and SLE. This represents a novel

281 mechanism of autoantibody development and SLE pathogenesis.

282 Living organisms are constantly exposed to a variety of pathogens including non-fatal

283 viruses that can invade the host if they circumvent host's CTL defense (82), as

284 exemplified by the recent re-emergence of measles infection in young adults. These

285 repeated rounds of infection, however, may be unapparent at the time of re-infection if

286 CTL memory has lapsed; prodromal signs are indeed minute in SLE. Such antigens, if

287 presented in combination with the appropriate host's HLA, may maximally stimulate the

288 host's TCR. The particular antigens that cause SLE may differ depending upon the host's

289 HLA, but they must be recognized by and must stimulate TCR maximally to levels

290 beyond its self-organized criticality. Upon encounter with peripherally expressed antigens

291 such as mouse mammary tumor virus (Mtv-8) or influenza haemagglutinin (HA), the CD4

292 T cells reactive against them are deleted or anergized $(83,84)$. However, further repeated

293 stimulation causes a few cells to be recovered from anergy, proliferate, and pass through 
294 TCR re-revision at the periphery, acquiring a $\mathrm{T}$ follicular helper-like phenotype

$295(77,78,83,84)$. Since these cells no longer react against the same antigens and reside in a

296 restricted space, splenic GC, immune response will cease (83). However, if further

297 stimulated by an 'immunogenic' viral form of influenza HA, the once-angergized T cells

298 will begin to proliferate (84), which is the TCR stimulus that surpass its self-organized

299 criticality. SLE-inducing DOCK $8^{+}$CD4 T cells are generated in this fashion. This newly-

300 generated DOCK8-expressing T follicular helper cells reside in the splenic red pulp, the

301 location immune reactive against a variety of antigens. Therefore, repeated stimulation

302 with 'immunogenic' antigen, either exogenous or endogenous, induces $a i \mathrm{CD} 4 \mathrm{~T}$ cells and

303 SLE, and the latter of which is consistent with the molecular mimicry theory. Further,

304 since SLE is unique in that a large variety of autoantibodies, sometimes exceeding 100

305 types, are generated in an individual $(85,86)$, it seems rational that SLE and

306 autoantibodies result from TCR re-revision at the periphery rather than reactivation of

307 forbidden clones. 
$310 \mathrm{BALB} / \mathrm{c}, \mathrm{B} 10 . \mathrm{D} 2, \mathrm{C} 57 \mathrm{BL} / 6$, and NZB/W F1 female mice were obtained from Japan SLC,

311 Inc., Hamamatsu, Japan. CD1d knockout (KO) mice of BALB/c background (C.129S2-

$\left.312 \mathrm{Cd} 1^{\mathrm{tm} 1 \mathrm{Gru}} / \mathrm{J}\right)$ were purchased from Jackson Laboratory (Bar Harbor, ME). All animal

313 experiments were conducted in accordance with the guidelines of the Kyushu University

314 Institution Review Board (Permission number A29-174-1) and the Review Board for

315 Experimental Studies of the Institute for Rheumatic Diseases (Permission number A2017-

316 001).

\section{Patients}

318 Human blood samples were studied in accordance with the guidelines of the Kyushu

319 University Institution Review Board for Human Genome/ gene research (Protocol 711-

320 00, approved on March 21, 2017).

\section{$321 \quad$ Reagents}

322 OVA (grade V) was purchased from Sigma, St.Louis, MO. Staphylococcus enterotoxin B

323 (SEB) and SEA were purchased from Toxin Technologies, Sarasota, FL. Alpha-

324 galactosylceramide ( $\alpha$ GalCer) was a gift of Pharmaceutical Research Laboratories, Kirin

325 Brewery Co., Ltd., Gunma, Japan. Carboxyfluorescein diacetate succinimidyl ester 
326 (CFSE; C34570, Cell Trace, CFSE Cell Proliferation kit), Protein G magnetic beads 327 (\#100-03D), and normal rabbit IgG (10500C) were purchased from Invitrogen, Thermo 328 Fisher Scientific, Shibaura, Tokyo, Japan. The following were purchased from Biolegend, 329 San Diego, CA: anti-B220-PE (RA3-6B2), anti-BST2-FITC (927), anti-CD3-PE/Cy7 330 (145-2C11), anti-CD4 Ab (GK1.5), anti-human CD4-PE Cy7 Ab (\#300511), anti-mouse 331 CD4-FITC and CD4-PerCP/Cy5.5 Abs (RM4-5), anti-CD5-FITC (53-7.3), anti-CD21332 FITC (7E9), anti-CD23-PE (B3B4), anti-CD23-Alexa Fluor 647 Ab (B3B4), anti-CD25333 PE Ab (PC61), anti-CD27-FITC Ab (LG.3A10), anti-CD43 activation-associated 334 glycoform-APC (1B11), anti-CD44-FITC Ab (IM7), anti-CD62L-APC Ab (MEL-14), anti-CD80-FITC (16-10A1), anti-CD83-FITC (Michel-19), anti-CD86-PE (GL-1), antihuman CD122-APC Ab (\#339007), anti-CD123-PE Ab (5B11), anti-CD138-PE (281-2), 337 anti-CCR4-PE/Cy7 Ab (2G12), anti-CD147-FITC (OX114), anti-CXCR5-FITC (L138D7), anti-CXCR5-APC Abs (L138D7), anti-DC9-PE/Cy7 (6D5), anti-FR4-FITC 339 (12A5), anti-GL7-FITC Ab (GL7), anti-GL7-PE (GL7), anti-ICOS-FITC Ab (C398.4A), 340 anti-rabbit IgG-PE Ab (\#406421), anti-rabbit IgG-FITC (Poly4064), IgG-PE Ab 341 (Poly4064), anti-LFA1-APC (H155-78), anti-IgM-FITC (RMM-1), anti-PD-1-APC Ab 342 (29F.1A12), anti-SiglecH-PE (551), anti-T-bet-Alexa Fluor 647 Ab (4B10), anti-Thy1.2343 APC (30-H12), and anti-TCR $\beta$-FITC (H57-597). Also purchased from Biolegend were 
344 ELISA kits for IFN $\gamma$, IL-2, IL-4, IL-6, IL-10, IL17 and IL-23. Rabbit anti-DOCK8 Ab

345 (11622-1-AP) was from Proteintech, Co. Ltd., Rosemont, IL. Anti-Bc16-PE (mGI191E), 346 anti-human CD45RB-Alexa Fluor 488 Ab (53-9458), anti-Foxp3-APC Ab (FJK-16s), 347 anti-GATA3-Alexa Fluor $488 \mathrm{Ab}$ (TWAJ) and anti-ROR $\gamma$ t-APC Ab (B2D), and ELISA 348 assay kits for TGF $\beta$, TNF $\alpha$, IL-21, and IL-22 were from eBioscience, San Diego, CA. 349 Anti-CD11c-APC (HL3), anti CD28 mAb (37.51), anti-Ly6C-FITC Ab (AL-21), anti350 TLR7-PE (A94B10), and anti-V $\beta 8$ TCR-PE (F23.1) were from BD Pharmingen, San 351 Diego, CA. Peanut agglutinin (PNA)-fluorescein (FL-1071), alkaline phosphatase avidin D (A-2100) and Animal-free Blocker were purchased from Vector Laboratories 353 (Burlingame, CA). HRP-anti-rabbit $\operatorname{IgG} \mathrm{Ab}$ and nonimmunized rabbit IgG were 354 purchased from Cappel Laboratories, Inc., Cochranville, PA. Anti-acetyl Histone H3 Ab 355 (acetylated H3K9, K14; 06-599) and anti-trimethyl Histone H3 Ab (Lys4; 07-473) were 356 purchased from Upstate Biotechnology Inc., Lake Pacid, NY. Anti-Histone H3 (trimethyl $357 \mathrm{~K} 4) \mathrm{Ab}(\mathrm{ChIP}$ grade; ab8580) and rabbit anti-IFN $\gamma$ (ab96575) Ab were purchased from 358 Abcam, Cambrige, UK. Dynabeads Protein G (DB10003) was from VERITAS, Tokyo, Japan. RNase A (19101) was purchased from Qiagen, Hilden, Germany. Proteinase K 360 (9033) was from TaKaRa Bio Inc., Kusatsu, Japan. Anti-rabbit Novolink (RE7112) was 361 purchased from Leica Camera Frankfurt, GmbH, Germany. Fast red (415261) was 
362 purchased from Nichirei Bioscience, Tokyo, Japan. Histogreen (E109) was from

363 LINARIS Biologische Produkte GmbH, Dossenheim, Germany. T4 DNA ligase was

364 purchased from Roche Diagnostics, Basel, Switzerland.

\section{Animal Studies}

366 BALB/c female mice ( 8 weeks old) or C57BL/6 mice ( 8 weeks old) were immunized

367 with $500 \mu \mathrm{g}$ OVA or PBS by means of i.p. injection every 5 days for a total of 12 injections.

368 Mice were analyzed 9 days after the final immunization. Mice were also immunized with

$36925 \mu \mathrm{g}$ SEB, $25 \mu \mathrm{g}$ SEA or PBS by means of i.p. injection every 5 days for a total of 8

370 injections, and analyzed thereafter. For adoptive cell transfer, CD4 T cells were isolated

371 from mouse spleens to $>90 \%$ purity using Ab-coated MACS beads (mouse CD4 T cell

372 isolation kit; Miltenyi Biotec., Germany). They were then incubated with anti-DOCK8

373 Ab followed by anti-rabbit IgG-coated MACS beads (Miltenyi Biotec.), and the isolated

374 cells $\left(2.5 \times 10^{7} /\right.$ mouse $)$ were transferred into naïve BALB/c mice by means of i.v. injection.

375 The recipient mice received a single i.p. injection of $500 \mu \mathrm{g}$ OVA $24 \mathrm{~h}$ after cell transfer,

376 and the sera, urine and the organ of recipients were studied 2 weeks afterwards. For

377 adoptive cell transfer into previously-immunized mice, BALB/c mice were first

378 immunized $8 \mathrm{x}$ with OVA, and $24 \mathrm{hr}$ after the final immunization, mice were administered

$379200 \mu \mathrm{g}$ anti-CD4 Ab (GK1.5) to deplete CD4 T cells. Four days later, DOCK8 ${ }^{+}$CD4 T 
cells from the mice immunized 12x with OVA were transferred into the CD4 T-depleted

381 mice. The recipient mice received a single i.p. injection of $500 \mu \mathrm{g}$ OVA $24 \mathrm{~h}$ after cell

382 transfer and were analyzed 2 weeks later.

383 For the SEB immunization study, BALB/c or CD1d KO female mice (8-15 weeks old)

384 were immunized with $25 \mu \mathrm{g}$ SEB, $25 \mu \mathrm{g}$ SEA, or $5 \mu \mathrm{g} \alpha \mathrm{GC}$ by means of i.p. injection every

3855 days for a total of 2 or 8 injections. Mice were bled $3 \mathrm{hr}$ after $2^{\text {nd }}$ and $8^{\text {th }}$ immunization,

386 and serum IL-2 and autoantibodies were measured by ELISA. To evaluate T cell division,

387 cells $\left(1 \times 10^{7} / \mathrm{ml}\right)$ were incubated with $10 \mu \mathrm{M}$ CFSE in PBS for $10 \mathrm{~min}$ and an equal volume

388 of FCS was added to quench the reaction. After washing, CFSE-labeled cells

$389\left(1 \times 10^{5} / 200 \mu \mathrm{l} / \mathrm{well}\right)$ were stimulated with $2 \mu \mathrm{g} / \mathrm{ml}$ of plate-bound anti-CD28 Ab for $72 \mathrm{hr}$,

390 and the number of mitotic events was measured by flow cytometry (FACSCalibur, Becton

391 Dickinson, San Jose, CA).

392 For therapeutic Ab treatment, BALB/c mice immunized with OVA were treated with anti-

393 DOCK8 Ab $(100 \mu \mathrm{g})$ or control rabbit $\operatorname{IgG}(100 \mu \mathrm{g}) 24 \mathrm{hr}$ before each of the $6 \mathrm{x}, 8 \mathrm{x}, 10 \mathrm{x}$

394 and 12x OVA immunizations, and analyzed 2 weeks later. The (NZBxNZW) F1 female

395 mice ( 8 weeks old) were treated either with anti-DOCK8 Ab $(100 \mu \mathrm{g})$ or control rabbit

$396 \operatorname{IgG}(100 \mu \mathrm{g})$ every 15 to 24 weeks, and blood and urine samples were analyzed weekly.

\section{Mass spectrometry analysis}


398 Cytosolic and membrane proteins were extracted from CD45RB ${ }^{\text {hi }}$ CD122 ${ }^{\text {hi }}$ CD4 T cells, $399 \mathrm{CD} 4 \mathrm{RB}^{\text {lo }} \mathrm{CD} 122^{\text {lo }} \mathrm{PD}-1^{-} \mathrm{CD} 4 \mathrm{~T}$ cells and $\mathrm{CD} 45 \mathrm{RB}^{\text {lo }} \mathrm{CD} 122^{\text {lo }} \mathrm{PD}-1^{+} \mathrm{CD} 4 \mathrm{~T}$ cells that 400 had been harvested from spleens of mice immunized 12x with OVA, as well as control 401 CD4 T cells derived from the spleen of mice treated 12x with PBS. One hundred million 402 cells were reacted with Extraction Buffer I (EMD Bioscience, Inc.) containing 1\% 403 protease inhibitor cocktail for $10 \mathrm{~min}$ at $4{ }^{\circ} \mathrm{C}$, and the supernatants containing cytosolic 404 proteins were taken. The pellets were reacted with Extraction Buffer II (EMD Bioscience, 405 Inc.) containing $1 \%$ protease inhibitor cocktail for $30 \mathrm{~min}$ at $4{ }^{\circ} \mathrm{C}$, and subjected to 406 centrifugation at 5,500 $\mathrm{x}$ for $10 \mathrm{~min}$, and the supernatants were taken as the membrane 407 protein fraction. Ten $\mu \mathrm{g}$ total protein per sample was fractionated by electrophoresis in a $10 \%$ polyacrylamide gel, and the gel was stained with silver nitrate. Representative 409 portions in the gel were cut out and digested with trypsin. Digested peptides were eluted 410 with $0.1 \%$ formic acid and subjected to LC-MS/MS analysis, performed on a Q-Tof 2 411 quadrupole/time-of-flight hybrid mass spectrometer (Waters Co, Milford, MA) interfaced 412 with a CapLC capillary reverse-phase LC system. The eluted peptides were sprayed 413 directly into the mass spectrometer. MS/MS data were acquired by MassLynx software 414 (Micromass) and converted into a single text file (containing the observed precursor 415 peptide $\mathrm{m} / \mathrm{z}$, the fragment ion $\mathrm{m} / \mathrm{z}$ and intensity value) by ProteinLynx software 
416 (Micromass). The file was analyzed using the Matrix Science Mascot MS/MS Ion Search

417 software (http://www.matrixscience.com) to search and assign the obtained peptides to

418 the NCBI non-redundant database. Proteins $(10 \mu \mathrm{g}$ each) were again subjected to

419 electrophoresis in $10 \%$ polyacrylamide gel, transferred to an Immobilon-P membrane

420 (Milipore, Bedford, MA), and stained sequentially with specific Ab and labelled 2ndary

$421 \mathrm{Ab}$.

422 In vitro autoantibody and cytokine assay

423 Sera were assayed 9days after final priming by ELISA for RF (FUJIFILM

424 Wako Shibayagi Co., Gunma, Japan), anti-dsDNA Ab (Worthington Biochemical Co.,

425 Lakewood, NJ), or anti-Sm Ab using Sm antigen (ImmunoVision, Springdale, AR).

426 Isolated DOCK $8^{+} \mathrm{CD} 4 \mathrm{~T}$ cell CD4 T cells $\left(1 \times 10^{6} / \mathrm{ml}\right)$ were stimulated with $2 \mu \mathrm{g} / \mathrm{ml}$ anti-

$427 \mathrm{CD} 3 \mathrm{Ab}$ and $5 \mu \mathrm{g} / \mathrm{ml}$ anti-CD28 $\mathrm{Ab}$ at $37^{\circ} \mathrm{C}$ for $24 \mathrm{hr}$, and the culture supernatants were

428 assayed for cytokines by ELISA.

429 Flow cytometry and cell sorting.

430 Lymphocyte surface markers of $\mathrm{T}$ and $\mathrm{B}$ cells of mice and human peripheral blood were

431 assayed using anti-CD4-FITC $\mathrm{Ab}$, anti-CD4-PerCP/Cy5.5 Ab or the respective Abs after

432 blocking non-specific FcR binding with anti-mouse CD16/32 Ab (Biolegend). For

433 DOCK8 staining, lymphocytes were treated with rabbit anti-DOCK8 Ab followed by 
434 staining with anti-rabbit IgG-FITC Ab or anti-rabbit IgG-PE Ab. For intracellular staining,

435 DOCK8-stained cells were fixed and permeabilized in fixation/ permeabilization solution

436 and permeabilization buffer from the Foxp3/ Transcription Factor Staining Buffer Set

437 (eBioscience). They were next stained with the respective Abs against Foxp3, T-bet,

438 GATA3 and ROR $\gamma \mathrm{t}$. Cells were washed once, resuspended in PBS and analyzed on a

439 FACSCallibur flow cytometer (BD Biosciences, San Jose, CA).

440 All antibodies have been validated by their suppliers and references can be found on their

441 websites or online validation databases. Dilutions were 1:5,000 for surface staining with

442 PNA-fluorescein, 1:1,000 for surface staining with anti-GL7-PE Ab, 1:200 for surface

443 staining with anti-CD4FITC Ab or anti-CD4-PerCP/Cy5.5 Ab, and 1:100 for the staining

444 with the other Abs.

445 For cell isolation, CD4 $\mathrm{T}$ cells, $\mathrm{DOCK} 8^{+} \mathrm{T}$ cells were isolated from spleens of mice to

$446>90 \%$ purity using Ab-coated MACS beads (Miltenyi Biotec, Germany). Cell numbers

447 were determined using AccuCheck Counting Beads (Life Technologies, Invitrogen)

448 according to manufacturer's instructions.

449 Pathological Studies

450 Pathological studies were done using $10 \%$ formalin-fixed and $\mathrm{H}-\mathrm{E}$ stained organ

451 specimens. For immunoperoxidase staining of $\mathrm{DOCK}^{+}$cells, specimens were serially 
reacted with anti-DOCK $8 \mathrm{Ab}$ and $\mathrm{HRP}$-anti-rabbit IgG $\mathrm{Ab}$ followed by diaminobenzidine

454 microscopic studies, CD4 T cells were isolated from the spleens of 12x OVA-immunized 455 mice to $>90 \%$ purity using Ab-coated MACS beads, pelleted by centrifugation, washed, 456 and stained directly with Au-conjugated goat anti-DOCK8 Ab RT for 4hr. They were then 457 washed with $\mathrm{PBS}$, fixed in $1 \% \mathrm{OsO}_{4}$ for $2 \mathrm{hr}$ at $4{ }^{\circ} \mathrm{C}$, and then dehydrated in graded 458 alcohol and embedded in Epon 812. Sections $90 \mathrm{~nm}$ thick were cut using an LKB ultramicrotome, counter-stained with uranyl acetate and lead, and observed under a Hitachi H-7600 electron microscope for Au-stained cells. Renal Pathology was classified according to SLE human renal disease classification (26). Spleens from patients with SLE and controls obtained at autopsy were fixed in 10\% formalin and embedded in paraffin.

463 Paraffin sections of $4 \mu \mathrm{m}$ thickness were deparaffinized by graded xylene and graded 464 alcohol sequentially, treated with $0.01 \mathrm{M}$ citric acid in an autoclave at $121^{\circ} \mathrm{C}$ for $10 \mathrm{~min}$, and blocked with Animal-free Blocker for 10min. Specimens were then treated with biotinylated anti-DOCK8 monoclonal $\mathrm{Ab}$ diluted at 1:200 and rabbit anti-interferon $\gamma \mathrm{Ab}$

467 diluted at $1: 1,000$ at $4^{\circ} \mathrm{C}$ for $24 \mathrm{hr}$. After blocking endogenous peroxidase with hydrogen peroxide RT for $15 \mathrm{~min}$, the specimens were reacted serially with alkaline phosphatase avidin D and anti-rabbit Novolink RT for 30min, followed by Fast red and Histogreen 
470 staining RT for $40 \mathrm{~min}$ and $2 \mathrm{~min}$, respectively. After washing, the specimens were air dried,

471 embedded, and observed under microscope.

472 RT-PCR for recombinase.

473 Total RNA was reversely transcribed to cDNA and amplified by PCR. The products were

474 fractionated by electrophoresis and transferred to nylon membranes (Roche Diagnostics,

475 Mannheim, Germany). The membranes were hybridized to fluorescein end-labelled

476 probes and visualized by alkaline phosphatase (ALP)-labeled anti-fluorescein antibody

477 and Gene Images CDP-Star chemiluminescence reaction (Amersham Pharmacia Biotech,

478 Piscataway, NJ). The primers and probes were: 5'-

479 CCAAGCTGCAGACATTCTAGCACTC-3'

480 CAACATCTGCCTTCACGTCGATCC-3' ${ }^{\prime}$ (reverse) 5' $^{\prime}$

481 AACATGGCTGCCTCCTTGCCGTCTACCCT-3' (probe) for RAG1 (87); 5'-

482 CACATCCACAAGCAGGAAGTACAC-3' $\quad$ (forward), 5'-

483 GGTTCAGGGACATCTCCTACTAAG-3' ${ }^{\prime}$ (reverse) 5'

484 GCAATCTTCTCTAAAGATTCCTGCTACCT-3' (probe) for RAG2 (87); 5'-

485 GAACAACTCGAAGAGCCTTCC-3'

486 CAAGGGCATCCGTGAATAGTTG-3' (reverse) and '

487 ATTCGGTCACCCACATTGTGGCAGAGAAC-3' (probe) for TdT; 5'- 
CAACTGGGTCATGCTTCTCC-3' (forward), 5'-TGGCTGTCGAAGATTCCC-3'

(reverse) and 5'-CCGTCTCTGGCTCCACCCATCACACTGCT-3' (probe) for pT $\alpha$.

\section{Next-generation sequencing of TCR genes}

491 One microgram total RNA from DOCK8 ${ }^{+}$CD4 T cells, DOCK8 ${ }^{-}$CD4 T cells, and CD4

492 T cells were each converted into complementary DNA (cDNA) with Superscript III 493 reverse transcriptase (Invitrogen, Carlsbad, CA). BSL-18E primer containing poly $\mathrm{T}_{18}\left(5^{\prime}\right.$ 494 AAAGCGGCCGCATGCTTTTTTTTTTTTTTTTTTVN-3') and an SphI site was used 495 for cDNA synthesis. Double stranded (ds)-cDNA was synthesized using E.coli DNA 496 polymerase I, E.coli DNA ligase and RNase H (Invitrogen). The ds-cDNA was then 497 blunted with T4 DNA polymerase (Invitrogen). P10EA/ P20EA adapter (5'GGGAATTCGG-3'/ 5'-TAATACGACTCCGAATTCCC-3') was ligated to the 5'end of

499 the ds-cDNA followed by digestion with $S p h$ I restriction enzyme (88). After removing 500 adaptor and primer by MinElute Reaction Cleanup kit (Qiagen), PCR was performed 501 using either specific for TCR $\alpha$-chain constant region (mCA1; 5'TCATGTCCAGCACAGTTTTG-3') or TCR $\beta$-chain constant region (mCB1; 5'503 AGGATTGTGCCAGAAGGTAG-3') and P20EA adaptor using KAPA HiFi DNA 504 Polymerase (Kapa Biosystems, Woburn, MA). Next, a second PCR was performed using 505 the P20EA and $2^{\text {nd }}$ PCR primers for TCR $\alpha$ (mCA2; 5'-GTTTTCGGCACATTGATTTG- 
506 3') or TCR $\beta$ (mCB2; 5'-TTGTAGGCCTGAGGGTCC-3'). Amplicons were

507 subsequently prepared by amplifying the second PCR products using P22EA-ST1-R Tag

508 primers

GTCTCGTGGGCTCGGAGATGTGTATAAGAGACAGCTAATACGACTCCGAATT

510 CCC-3') and mCA-ST1-R Tag primer for TCR $\alpha$ (5'-TCGTCGGCAGCGTCAGAT

511 GTGTATAAGAGACAGGTGGTACACAGCAGGTTCT-3') or mCB-ST1-R Tag

512 primer for $\quad$ fCR $\beta$

513 TCGTCGGCAGCGTCAGATGTGTATAAGAGACAGGTTGGGTGGAGTCACATTT-

514 3'). After PCR amplification, index (barcode) sequences were added by amplification

515 with the Nextera XT Index kit v2 setA or setD (illumine, San Diego, CA). The indexed

516 amplicon products were mixed in equal molar concentrations and quantified by a Qubit

5172.0 Fluorometer (Thermo Fisher Scientific, Waltham, MA). Sequencing was performed

518 using the Illumina Miseq paired-end platform (2x300bp). All the paired-end reads were

519 classified by index sequences. All sequence reads were classified by MID Tag sequences.

520 Artificially added sequences and sequences with low quality scores were removed from

521 both terminals of sequence reads using software installed on the 454 sequencing system

522 (88). The remaining sequences were used for assignment of TRAV and TRAJ for TCR $\alpha$

523 sequences, and TRBV and TRBJ for TCR $\beta$ sequences. Sequences were assigned by 
524 determining highest identity in a data set of reference sequences for all TRAV, TRAJ,

525 TRBV and TRBJ genes including pseudogenes and open reading frame (ORF) reference

526 sequences available from the international ImMunoGeneTics information system ${ }^{\circledR}$

527 (IMGT) database (http://www.imgt.org). Data processing, assignment, and data

528 aggregation were automatically performed using repertoire analysis software RG

529 (Repertoire Genesis Inc., Osaka, Japan), which implemented a program for sequence

530 homology searches using BLATN, an automatic aggregation program, a graphics program

531 for gene usage, and CDR3 length distribution (90). Sequence identities at the nucleotide

532 level between query and entry sequences were automatically calculated by carefully

533 optimizing for respective repertoires for parameters that increased sensitivity and

534 accuracy; i.e. E-value threshold, minimum kernel, and high-scoring segment pair (HSP)

535 score. CDR3 sequences were defined as the sequences ranging from a conserved Cysteine

536 at position 104 (Cys104) in the IMGT nomenclature to a conserved Phenylalanine

537 (Phe118) or Tryptophan (Trp118) at position 118, and these, together with the next

538 Glycine (Gly119), were translated into the deduced amino acid sequences (89). A unique

539 sequence read (USR) was defined as a sequence read having no identity with other

540 sequence reads in TRV, TRJ and deduced CDR3 amino acid sequences. The copy number

541 of identical USR was automatically counted by the RG software in each samples and 
542 ranked by copy number. Percentage frequencies of sequence reads within TRAV, TRAJ,

543 TRBV and TRBJ genes to total sequence reads were calculated. To estimate TCR

544 diversity in deep sequencing data, several diversity indices were used, including

545 Shannon-Weaver index $H^{\prime}$ and inverted Simpson index $1 / \lambda$. U, unique read and copy

546 numbers were used for species and individuals in these equations $(47,48)$.

\section{Gene Expression Microarray Assay}

548 Total RNA was extracted with the RNeasy Mini Kit (Qiagen, Hilden, Germany), and total

549 RNA was quantified by absorbance at $260 \mathrm{~nm}$ using a Nano Drop 2000 spectrophotometer

550 (Thermo Fisher Scientific, MA. USA). RNA samples were quantified by an ND-1000

551 spectrophotometer (NanoDrop Technologies, Wilmington, DE) and the quality was

552 confirmed with the Experion System (Bio-Rad Laboratories, Hercules, CA). The mRNA

553 expression profile was determined using a SurePrint G3 mouse GE Microarray $(8 \times 60 \mathrm{~K}$

554 v2) (Agilent Technology, Santa Clara, CA), and assay was performed by Cell Innovator

555 Inc. (Fukuoka, Japan). Relative hybridization intensities and background hybridization

556 values were calculated using Agilent Feature Extraction Software (9.5.1.1). Raw signal

557 intensities and Flags of two samples were calculated from hybridization intensities using

558 gProcessedSignal and spot information using gIsSaturated module in Bioconductor

559 software (91). The data was $\log _{2}$-transformed and normalized by quantile algorithm with 
560 'preprocessCore' library package (90). Probes named 'P' flag were set at least in one

561 sample, and Z-scores (92) and ratios (non-log scaled fold-change) from normalized signal

562 intensities of each probe for comparison between control and experiment sample were

563 calculated. The genes for which the $\mathrm{Z}$ score and the ratio were above 2.0 and 1.5,

564 respectively, were considered up-regulated. In contrast, the genes for which the Z scores

565 and ratios were below -2.0 and 0.66 , respectively, were considered down-regulated. Data

566 Analysis consisted of Flag criteria on GeneSpring Software which classified the results

567 as A: absent, indicating that the feature was not-positive and significant and that the

568 feature was not above background; M: marginal, indicating that the feature was not

569 uniform, saturated and a population outlier; P: present, indicating values other than A or

$570 \mathrm{M}$

571 Autoantibody Microarray Assay

572 Antigens diluted to optimal concentration were spotted in duplicate and random fashion

573 using Microgrid II micro-arrayer onto Nitrocellulose-coated 16-pad FAST ${ }^{\mathrm{TM}}$ slides

574 (Whatman Schleicher \& Schleicher BioScience, Keene, NH) (93). A 16-section frame

575 was applied to each slide to separate individual assays. After washing with blocking PBS

576 buffer containing 1\% bovine serum albumin and Tween, sera diluted 1:100 with blocking

577 buffer were added, and incubated with Cy3-labelled anti-mouse IgG. The arrays were 
578 washed with buffer, and the frames were removed. The slides were immersed in PBS and

579 then spun dry. A Genepix 4000B scanner with 532nm laser wavelength was used to

580 generate Tif images for analysis (94).

\section{Chromatin immunoprecipitation (CHIP) assay}

582 Forty million cells were suspended in $1 \mathrm{ml} \mathrm{RPMI}$, to which $0.1 \mathrm{ml}$ of $11 \%$ formaldehyde

583 was added and the tube rocked RT for $5 \mathrm{~min}$. Next, $0.1 \mathrm{ml}$ of $1.5 \mathrm{M}$ glycine was added to

584 terminate crosslinking. Cells were pelleted $\left(3 \mathrm{~K} \mathrm{x} \mathrm{g,} 5 \mathrm{~min}, 4^{\circ} \mathrm{C}\right)$, and dissolved in $1 \mathrm{ml}$

585 FACS solution (PBS containing $2 \% \mathrm{FBS}$ and $0.05 \% \mathrm{NaN}_{3}$ ) and washed. After the second

586 wash, cells were suspended in $0.2 \mathrm{ml}$ SDS lysis buffer $(50 \mathrm{mM}$ Tris- $\mathrm{HCl}, \mathrm{pH} 8.0,10 \mathrm{mM}$

587 EDTA, and 1\%SDS) containing 1\% Protease inhibitor cocktail on ice for 10 min.

588 Chromosomal DNA was sheared using a Bioruptor UCD-200 on ice for $10 \mathrm{~min}$. After

589 centrifugation at $14 \mathrm{~K} \times \mathrm{g}, 4^{\circ} \mathrm{C}$ for $10 \mathrm{~min}$, the supernatant was transferred to a $2 \mathrm{ml}$

590 siliconized tube. The chromatin sample was stored by addition of $0.1 \mathrm{vol} 50 \%$ glycerol at

$591-80^{\circ} \mathrm{C}$. Fifty $\mu 1$ Dynabeads Protein $\mathrm{G}$ were washed twice with Blocking solution (PBS

592 containing $0.5 \%$ BSA), dissolved in $0.5 \mathrm{ml}$ of the same, and loaded with $5 \mu \mathrm{g}$ of anti-acetyl

593 histone $\mathrm{H} 3 \mathrm{Ab}$, anti-trimethyl-Histone H3 Ab (Lys4), or normal rabbit IgG. After loading,

594 the pellets were washed twice with Blocking solution. For ChIP analyses, Dynabeads

595 Protein $\mathrm{G}$ were diluted with $1.8 \mathrm{ml} \mathrm{ChIP}$ dilution buffer at $4^{\circ} \mathrm{C}$. Chromatin derived from 
5962 million cells was used for each ChIP experiment with each antibody. The chromatin

597 samples were then added to the rabbit Ig-loaded beads and rocked at $4^{\circ} \mathrm{C}$ for $6 \mathrm{hr}$. Beads

598 were spun down at $15 \mathrm{~K} \mathrm{x} \mathrm{g}, 4^{\circ} \mathrm{C}$ for $2 \mathrm{~min}$, and $2 \mathrm{ml}$ supernatants were divided into 2 tubes,

599 from which $980 \mu \mathrm{l}$ was transferred to new tubes containing a second batch of rabbit Ig-

600 loaded beads, and rocked $1 \mathrm{hr}$ at $4^{\circ} \mathrm{C}$. These were next washed $5 \mathrm{x}$ with RIPA buffer

601 (50mM HEPES-KOH, pH7.6, 500mM LiCl, 1mM EDTA, pH8.0, 1\% NP-40, and 0.7\%

602 sodium deoxycholate) and once with TE buffer (10mM Tris-HCl, pH8.0, 1mM EDTA,

603 and $50 \mathrm{mM} \mathrm{NaCl}$ ). Twenty $\mu$ l was used as $1 \%$ Input. Beads were reacted with $210 \mu$ of

604 ChIP direct elution buffer (10mM Tris-HCl, 300mM NaCl, 5mM EDTA, and 0.5\% SDS)

605 at $65^{\circ} \mathrm{C}$ for $30 \mathrm{~min}$ with rotation. After centrifugation at $15 \mathrm{~K} \mathrm{x} \mathrm{g}$, RT for $1 \mathrm{~min}, 200 \mu \mathrm{l}$ of

606 supernatant was incubated at $65^{\circ} \mathrm{C}$. The $2 \%$ input chromatin was treated identically. Two

607 hundred $\mu \mathrm{l}$ of the supernatant was mixed with RNase A (final $0.2 \mathrm{mglml}$ ), rotated, spun

608 down and incubated at $37^{\circ} \mathrm{C}$ for $30 \mathrm{~min}$. Subsequently, proteinase $\mathrm{K}$ (final $0.2 \mathrm{mg} / \mathrm{ml}$ ) was

609 added, the sample rotated, spun down and incubated at $55^{\circ} \mathrm{C}$ for $1 \mathrm{hr}$. DNA was then

610 extracted using the QIA quick PCR purification kit, and reacted with TCR locus primers

611 by PCR at $94^{\circ} \mathrm{C}$ for $10 \mathrm{~min}$, followed by PCR amplification at $94^{\circ} \mathrm{C} 30 \mathrm{~s}, 58^{\circ} \mathrm{C} 1 \mathrm{~min}$, and

$61272^{\circ} \mathrm{C} 1 \mathrm{~min}$ for 35 cycles, and incubation at $72^{\circ} \mathrm{C}$ for $10 \mathrm{~min}$. PCR products $(10 \mu \mathrm{l})$ were

613 applied to a $2 \%$ agarose gel. The primer and probe sequences were shown in 
614 Supplementary Table 3. Input chromatin samples were diluted so that IP and input

615 samples would give approximately equal qPCR signals if $2 \%$ of the region of interest

616 were present in the IP sample.

617 Ligation-mediated PCR (LM-PCR)

618 Genomic DNA ( $1 \mu \mathrm{g})$ was ligated to 20 pmols BW linker, which was made by annealing

619 the oligonucleotides BW-1 and BW-2, in $50 \mu \mathrm{L}$ of reaction buffer containing $66 \mathrm{mM}$ Tris$\mathrm{HCl}(\mathrm{pH} 7.5), 5 \mathrm{mM} \mathrm{MgCl} 2,5 \mathrm{mM}$ DTT, $1 \mathrm{mM}$ ATP and $2.5 \mathrm{U}$ of T4 DNA ligase (Roche)

621 for 16 hours at $16^{\circ} \mathrm{C}$. Ligated DNA was diluted with an equal volume of a buffer 622 containing $10 \mathrm{mM}$ Tris (pH8.3), $50 \mathrm{mM} \mathrm{KCl,} 0.5 \%$ Nonidet P-40 (NP-40) and 0.5\%

623 Tween20 and heated for $15 \mathrm{~min}$ at $95^{\circ} \mathrm{C}$. Ligated DNA (100 ng) was amplified for 12 624 cycles with the locus-specific primer for first PCR and linker-specific primer BW-1H.

625 For nested LM-PCR reactions, $1 \mu \mathrm{L}$ of the products was then amplified for another 27

626 cycles with the locus-specific primer for nested PCR and BW-1H. The LM-PCR products 627 were fractionated by electrophoresis and transferred to Hybond $\mathrm{N}^{+}$membranes (GE 628 Healthcare, Buckinghamshire, England). The membranes were hybridized to alkaline 629 phosphatase (ALP)-labeled probes and visualized by Gene Images CDP-Star 630 chemiluminescence reaction (GE Healthcare). The sequences of the linkers and linker631 specific primers were; 
$6333^{\prime}$ for BW-2 linker and 5'-CCGGGAGATCTGAATTCCAC -3' for BW-1H primer. The 634 sequences of the locus-specific primers and probes were as follows: 5'635 TTACAAGAACTCCCTCTGCCTCTC-3' for first PCR, 5'636 AAGACACACTGGCTAGAGTTCTGGT-3' for nested PCR and 637 5'AGATGCCTAGGCTTCTGTAAAGGTGTCACCTGCAGTGGAATTCAG-3'

638 (probe) for signal end (SE) of $\mathrm{J} \alpha 2(\mathrm{~J} \alpha 2 \mathrm{SE})$;

639 5'-AGGAGATGCAAGCAAAGGAGTT-3' for first PCR, 5'640 AgGCAGAATtCGACTTGAgtAAG G-3' for nested PCR and 5'641 ACCTGTGGGTGTTTTTGACTGACTAAGAAACACTGTGGAATTCAG-3' (probe) 642 for Ja12 SE; 5'-GAACACAGAAGAAGGCCCAATATC-3' for first PCR, 5'643 AAAAGGAGATCAGAGAGGGGTGTT-3' for nested PCR and 5'644 CTGGGGACGCCATTTTGTAGACGTGTTTGTCACAGTGGAATTCAG-3' (probe) 645 for Ja24 SE; 5'-GCCTCTGTGGTCTAGTGTTTCTCA-3' for first PCR, 5'646 TGAGAACTTTACCCAGGAGGAAGA-3' for nested PCR and 5'647 CTCTGAGGAAGTTTTTGTTGTAGAGTCAGCCACTGTGGAATTCAG-3' (probe) 648 for Ja35; 5'-GTCAAAGCACCCAGAATAAAGAGG-3' for first PCR, 5'649 CCTGCACTATCACTGACTGTTTCC-3' for nested PCR and 5'650 CCTTACCTTGGTTTATGTAGAGACACAGAACACTGTGGAATTCAG-3' (probe) 
651 for Ja40 SE; 5'-CAATGGAGGGAAACAACACTAGC-3' for first PCR, 5'652 AgAagCtAGGGAATCAGGGAGAAT-3' for nested PCR and 5'653 GATGCCACGAGTTTTTGCAAAGCCCTTCAGTGCAGTGGAATTCAG-3' (probe) 654 for J $\alpha 58$ SE.

655 Anti-DOCK8 monoclonal Ab

656 Recombinant GST/His-tagged mouse DOCK8 encompassing the DHR1 domain (N657 terminal 561-730 amino acids; Uniprot accession number Q8C147), was expressed in E. 658 coli. After capturing on glutathione sepharose column, His-tagged mouse DOCK8 was 659 eluted by protease-digestion, and fractionated with size-exclusion chromatography. Using 660 this purified antigen, anti-DOCK8 antibodies were generated from non-immune phage 661 antibody libraries developed in KAN Research Institute. Purified His-tagged mouse 662 DOCK8 was immobilized on Dynabeads M280-Tosylactivated (Thermo Fisher Scientific, 663 Waltham, MA), and monoclonal single chain Fvs (scFvs) were selected by 3x repeated 664 reaction with the beads, followed by interaction with His-tagged mouse DOCK8 coated 665 onto MaxiSorp immunotubes (Thermo Fisher Scientific). Monoclonal scFvs picked from 666 the $3^{\text {rd }}$ and $4^{\text {th }}$ rounds of selection were expressed as bacterial supernatants. Positive scFvs 667 were identified by ELISA reactive against His-tagged mouse DOCK8. ELISA-positive 668 scFvs obtained were sequenced and genetically converted to human IgG format. Anti- 
669 DOCK8 mAbs were expressed in the Expi293 system (Thermo Fisher Scientific) and

670 purified by Protein A resin. The anti-DOCK8 IgG mAbs thus obtained were validated by

671 size-exclusion chromatography, ELISA reactive against His-tagged mouse DOCK8561-730,

672 and intracellular staining of mouse $\mathrm{CD}^{+} \mathrm{T}$ cells by flow-cytometry. Finally, mAb

673 generated were used for staining DOCK $8^{+}$CD4 T cells from SLE patients and control

674 individuals. DOCK $8^{+} \mathrm{CD} 4 \mathrm{~T}$ cells in the peripheral blood were stained with anti-DOCK8

$675 \mathrm{mAb}$ and anti-rabbit IgG, and $\mathrm{DOCK} 8^{+} \mathrm{CD} 4 \mathrm{~T}$ cell fraction within the each patient's CD4

676 T cells were compared with individual SLE disease activity indices (SLEDAI) (40).

\section{Acknowledgements}

679 We thank Dr. Marc Lamphier for useful discussion and English edition, Prof. Nancy J.

680 Olsen, Penn State M.S. Hershey Medical Center, for useful discussion and kind

681 arrangements for autoantibody microarray, Prof. Emeritus Takashi Sawai, Sendai Open

682 Hospital, for useful discussion and transfer of autopsy specimens, and Dr. Hiroshi Ishii,

683 Oita Red Cross Hospital, for providing peripheral blood samples of patients under

684 written consent of the Kyushu University Institution Review Board (Protocol 711-00).

685 This study was supported by the grant of Institute for Rheumatic Diseases, and the grant-

686 in-aid 25515003, 17659301, 13204059, 11557026, 12204074, 13204059, and the Global 
687 Center of Excellence (COE) Program grant of the Ministry of Education, Culture, Sports,

688 Science and Technology of Japan; the New Industry Research Organization grant 0003;

689 the Japan Science and Technology Organization to S.S, and the grant-in-aid 18K06933 of

690 the Ministry of Education, Culture, Sports, Science and Technology of Japan to K.T.

691 Author contributions

692 S.S. conceived and designed the study, identified DOCK8 as aiCD4 T marker, performed

693 EM and pathology studies, interpreted results, and wrote the manuscript. K.T. performed

694 cell transfer studies, FACS, WB, RT-PCR and cytokine measurements, and prepared

695 samples for and reconstructed the data of autoantibody microarray and TCR repertoire

696 next generation assays. Y.M. isolated and fractionated CD4 T cells to

697 CD45RBloCD122loPD-1 ${ }^{+}$fraction. K.U. performed CHIP-seq and LM-PCR studies.

698 K.Sakurai performed B cell assay. T.Nakashima, H.M., C.S., A.D., Y.F., and M.T.

699 performed anergy and mechanism of aiCD4 T cell induction studies. T.Nakashima and

700 Y.N. studied NKT cell help for aiCD4 T cell induction. M.I. performed OVA-induced

701 aiCD4 T cell in C57BL/6 mice study. Q-Z. L. performed autoantibody microarray assay.

702 K. M. and Y. M. produced anti-DOCK8 mAb. K.M., T.E., S.T., Y.H. and M.M. performed

703 human pathology studies. M.M. performed, evaluated blindly, and organized the mouse

and human pathology studies. T. H., T. M., M. O., T. Y., H. K. and S.S. enabled portions 
705 of, and K.S. enabled most of patients study under written consent based on Kyushu

706 University Institution Review Board (Protocol 711-00).

707 
708 1. Theofilopoulos, A. N., Baccala, R., Beutler, B., \& Kono, D.H. Type I interferons

709 (alpha/beta) in immunity and autoimmunity. Ann. Rev. Immunol. 23, 307-336 (2005).

710 2. Crow, Y. J., Lebon, P., Casanova, J-L., \& Gressor, I. A brief historical perspective

711 on the pathological consequences of excessive type I interferon exposure in vivo. J.

712 Clin. Immunol. 38, 694-98 (2018).

713 3. Chasset, F., \& Arnaud, L. Targeting interferons and their pathways in systemic

714 lupus erythematosus. Autoimmun. Rev. 17, 44-52 (2018).

715 4. Hooks, J. J., Moutsopoulos, H.M., Gais, S.A., Stahl, N.I., Decker, J.L., \& Notkins,

716 A.L. Immune interferon in the circulation of patients with autoimmune disease. N. Engl.

717 J. Med. 301, 5-8 (1979).

718 5. Preble, O. T., Black, R.J., Friedman, R.J., Klippel, J.H., \& Vilcek, J. Systemic lupus

719 erythematosus: presence in human serum of an unusual acid-labile leukocyte interferon.

720 Science 216, 429-431 (1982).

721 6. Yutterberg, S. R., \& Schnitzer, T.J. Serum interferon levels in patients with systemic

722 lupus erythematosus. Arthritis Rheum. 25, 401-406 (1982).

723 7. Shiozawa, S., Kuroki,Y., Kim, Y., Hirohata, S., \& Ogino, T. Interferon-alpha in

724 lupus psychosis. Arthritis Rheum. 35, 417-422 (1992). 
725 8. Shiozawa, S. et al. A sensitive radioimmunoassay for alpha-interferon: circulating

$726 \alpha$-interferon-like substance in the plasma of healthy individuals and rheumatoid

727 arthritis patients. Clin. Exp. Immunol. 66, 77-87 (1986).

728 9. Bennett, L. et al. Interferon and granulopoiesis signatures in systemic lupus

729 erythematosus blood. J. Exp. Med. 197, 711-723 (2003).

730 10. Bauer, J. W. et al. Interferon-regulated chemokines as biomarkers of systemic

731 lupus erythematosus disease activity: a validation study. Arthritis Rheum. 60, 3098-

7323107 (2009).

733 11. Ronnblom, L. E., Alm, G.V. \& Oberg, K.E. Autoimmunity after-interferon therapy

734 for malignant carcinoid tumors. Ann. Intern. Med. 115, 178-183 (1991).

735 12. Mathian, A., Weinberg,A., Gallegos, M., Banchereau, J. \& Koutouzov, S. IFN- $\alpha$

736 induces early lethal lupus in preautoimmune (New Zealand Black x New Zealand

737 White) F1, but not in Balb/c mice. J. Immunol. 174, 2499-2506 (2005).

738 13. Fairhurst, A.M. et al. Systemic IFN-alpha drives kidney nephritis in B6.Sle123

739 mice. Eur. J. Immunol. 38, 1948-1960 (2008).

740 14. Santiago-Raber, M-L. et al. Type-I interferon receptor deficiency reduces lupus-

741 like disease in NZB mice. J. Exp. Med. 197, 777-788 (2003). 
742 15. Nacionales, D. C. et al. Deficiency of the type I interferon receptor protects mice

743 from experimental lupus. Arthritis Rheum. 56, 3770-3783 (2007).

744 15. Baccala, R. et al. Anti-IFN- $\alpha / \beta$ receptor antibody treatment ameliorates disease in 745 lupus-predisposed mice. J. Immunol. 189, 5976-5984 (2012).

746 16. Akiyama, C. et al. Conditional upregulation of IFN- $\alpha$ alone is sufficient to induce

747 Systemic Lupus Erythematosus. J. Immunol. 203, 835-843 (2019).

748 17. Hron, J. D. \& Peng, S.L. Type I IFN protects against murine lupus. J. Immunol. 173, $749 \quad 2134-2142(2004)$

750 18. Li, J., Liu, Y., Xie, C., Zhu, J., Kreska, D., Morel, L. \& Mohan, C. Deficiency of 751 type I interferon contributes to Sle2-associated component lupus phenotypes. Arthritis 752 Rheum. 52, 3063-3072 (2005).

753 19. Tolaymat, A., Leventhal, B., Sakarcan, S., Kashima, H. \& Monteiro, C. Systemic

754 lupus erythematosus in a child receiving long-term interferon therapy. J. Pediatr. 120, $755 \quad 429-432$ (1992).

756 20. Schilling, P. J., Kurzrock, R., Kantarjian, H., Gutterman, J.U. \& Talpaz, M.

757 Development of systemic lupus erythematosus after interferon therapy for chronic 758 myelogenous leukemia. Cancer 68, 1536-1537 (1991). 
760 (rhuMAb interferon- $\alpha$ ) in patients with systemic lupus erythematosus. Ann. Rheum.

761 Dis. 75, 196-202 (2016).

762 22. Khamashta, M. et al. Sifaimumab, an anti-interferon- $\alpha$ monoclonal antibody, in

763 moderate to severe systemic lupus erythematosus: a randomised, double-blind, placebo-

764 controlled study. Ann. Rheum. Dis. 75: 1909-1916 (2016).

765 23. Furie R. et al. Anifrolumab, an anti-interferon- $\alpha$ receptor monoclonal antibody, in 766 moderate-to-severe Systemic Lupus Erythematosus. Arthritis Rheumatol. 69, 376-386 767 (2017).

768 24. Tsumiyama K., Miyazaki, Y. \& Shiozawa, S. Self-organized criticality theory of 769 autoimmunity. PLoS One 4(12), 8382 (2009). 25. Tsumiyama, K., Hashiramoto, A., Takimoto, M., Tsuji-Kawahara, S., Miyazawa, M. \& Shiozawa, S. IFN- $\gamma$-producing effector CD8 T lymphocytes cause immune glomerular injury by recognizing antigen presented as immune comples on target tissue. J. Immunol. 191, 91-96 (2013).

774 26. Weening, J.J. et al. The classification of glomerulonephritis in systemic lupus erythematosus revisited. J. Am. Soc. Nephrol. 15, 241-50 (2004). 
777 lupus erythematosus. Bull. Johns Hopkins Hosp. 71:31-43 (1942).

778 28. Breitfeld, D. et al. Follicular B helper T cells express CXC chemokine receptor 5, 779 localize to B cell follicles, and support immunoglobulin production. J. Exp. Med. 192, $780 \quad 1545-52(2000)$

29. Schaerli, P., Willimann, K., Lang, A.B., Lipp, M., Loetscher, P. \& Moser, B. 2000.

782 CXC chemokine receptor 5 expression defines follicular homing T cells with B cell

783 helper function. J. Exp. Med. 192, 1553-62 (2000).

30. Kunzli, M., D. et al. Long-lived T follicular helper cells retain plasticity and help sustain humoral immunity. 2020. Science Immunol. 5(45) pil: eaay5552 (2020). helper cells. Eur. J. Immunol. 43, 3219-3232 (2013).

32. Stebegg, M., Kumar, S.D., Silva-Cayetano, A., Fonseca, V.R., Linterman, M.A. \&

789 Graca, L. Regulation of the germinal center response. Front. Immunol. 9, article 2469 769 (2008). 
794 34. Chauveau, S. et al. Visualization of T cell migration in the spleen reveals a network

795 of perivascular pathways that guide entry into T zones. Immunity 52, 794-807 (2020).

796 35. Odegard, J.M. et al. ICOS-dependent extrafollicular helper T cells elicit IgG

797 production via IL-21 in systemic autoimmunity. J. Exp. Med. 205, 2873-2886 (2008).

798 36. Arnon, T.I., Horton, R.M., Grigorova, L.L. \& Cyster, J.G. Visualization of splenic

799 marginal zone B-cell suttling and follicular B-cell egress. Nature 493, 684-690 (2013).

800 37. William, J., Euler, C., Christensen, S. \& and Shlomchik, M.J. Evolution of

801 autoantibody responses via somatic hypermutation outside of germinal centers. Science $802 \quad 297,2066-2070(2002)$.

803 38. Enders, M. et al. Splenic red pulp macrophages cross-prime early effector CTL that

804 provide rapid defense against viral infections. J. Immunol. 204, 87-100 (2020).

805 39. La Muraglia II, G.M., Wagener, M.E., Ford, M.L. \& and Badell, I.R. Circulating T

806 follicular helper cells are a biomarker of humoral alloreactivity and predict donor-

807 specific antibody formation after transplantation. Am. J. Transpl. 20, 75-87 (2020).

808 40. Bombardier, C. et al. Derivation of the SLEDAI. Arthritis Rheum. 35, 630-640

809 (1992). 
810 41. Lantelme, E. et al. Recombinase-activating gene expression and V(D)J

811 recombination in CD4+CD3low mature T lymphocytes. J. Immunol. 164, 3455-3459

812 (2000).

813 42. Roose, J.P. et al. T cell receptor-independent basal signaling via Erk and Abl kinases

814 suppresses RAG gene expression. PLOS Biol. 1:271-287 (2003).

815 43. Patra, A.K. et al. PKB rescues calcineurin/NFAT-induced arrest of Rag expression

816 and pre-T cell differentiation. J. Immunol. 177, 4567-4576 (2006).

817 44. Naik, A.K., Byrd, A.T., Lucander, A.C.K. \& Krangel, M.S. Hierarchical assembly

818 and disassembly of a transcriptionally active RAG locus in CD4+CD8+ thymocytes. J.

819 Exp. Med. 216 231-243 (2018).

820 45. Ho, I.C. et al. Human GATA3: a lineage-restricted transcription factor that regulates

821 the expression of the T cell receptor $\alpha$ gene. EMBO J. 10, 1187-1192 (1991).

822 46. Ting, C-N., Olson, M.C., Barton, K.P. \& Leiden, J.M. Transcription factor GATA3 is

823 required for development of the T-cell lineage. Nature 384, 474-478 (1996).

824 47. Simpson, E.H. Measurement of diversity. Nature 163,588 (1949).

825 48. Shannon, C.A. Mathematical theory of communication. Bell Syst. Tech. J.

$826 \quad 27,379-423$ (1948). 
49. Harada, Y. et al. DOCK8 is a Cdc42 activator critical for intestinal dendritic cell

828 migration during immune responses. Blood 119, 4451-4461 (2012).

829 50. Cote, J-F., Motoyama, A.B., Bush, J.A. \& Vuori, K. A novel and evolutionarily

830 conserved PtdIns (3,4,5)P3-binding domain is necessary for DOCK180 signalling. Nat.

831 Cell Biol. 7, 797-807 (2005).

832 51. Premkumar, L., Bobkov, A.A., Patel, M., Jaroszewski, L., Bankston, L.A., Stec, B.,

833 Vuori, K., Cote, J-F. \& Liddington, R.C. Structural basis of membrane targeting by the

834 Dock180 family of Rho family guanine exchange factors (Rho-GEFs). J. Biol. Chem.

$835 \quad 285,13211-13222(2010)$.

836 52. Sadhukhan, S., Sarkar, K., Taylor, M., Candotti, F. \& Vyas, Y.M. Nuclear role of

837 WASp in gene transcription is uncoupled from its ARP2/3-dependent cytoplasmic role

838 in actin polymerization. J. Immunol. 193, 150-160 (2014).

839 53. Taylor, M.D. et al. Nuclear role of WASp in the pathogenesis of dysregulated Th1

840 immunity in human Wiscott-Aldrich syndrome. Sci. Transl. Med. 2, issue37 37ra44

841 (2010).

842 54. Rothenberg, E.V., Hosokawa, H. \& Ungerback, J. Mechanisms of action of

843 hematopoietic transcription factor PU.1 in initiation of T-cell development. Front.

844 Immunol. 10, article 228, 1-23 (2019). 
845 55. Takahashi, K. \& Yamanaka, S. A decade of transcription factor-mediated

846 reprogramming to pluripotency. Nat. Rev. Mol. Cell Biol. 17, 183-193 (2016).

847 56. Ippolito, G.C. et al. Dendritic cell fate is determined by BCL11A. PNAS E998-

848 E1006 (2014).

849 57. Lee, B-S. et al. Corrected and republished from: BCL11A is a critical component of

850 a transcriptional network that activates RAG expression and V(D)J recombination. Mol.

851 Cell Biol. 38(1), e00362-17 (2018).

852 58. Bergqvist, I., M.et al. The basic helix-loop-helix transcription factor E2-2 is

853 involved in T lymphocyte development. Eur. J. Immunol. 30. 2857-2863 (2000).

854 59. Jain, N., K. et al. Targetable genetic alterations of TCF4 (E2-2) drive

855 immunoglobulin expression in diffuse large B-cell lymphoma. Sci. Transl. Med. 11, 497

856 (2019).

857 60. Kovalovsky, D. et al. $\beta$-catenin/Tcf determines the outcome of thymic selection in

858 response to $\alpha \beta$ TCR signaling. J. Immunol. 183, 3873-3884 (2009).

859 61. Staal, F.J.T., Luis, T.C. \& Tiemessen, M.M. WNT signaling in the immune system:

860 WNT is spreading its wings. Nat. Rev. Immunol. 8, 581-593 (2008). 
861 62. Yang, X.O., Doty, R.T., Hicks, J.S. \& Willerford, D.M. Regulation of T-cell

862 receptor D $\beta 1$ promoter by KLF5 through reiterated GC-rich motifs. Blood 101, 4492-

$8634499(2003)$.

864 63. Yang, X.O., Doty, R.T., Hicks, J.S. \& Willerford, D.M. Regulation of T-cell

865 receptor D1 promoter by KLF5 through reiterated GC-rich motifs. Blood 101, 4492-

$8664499(2003)$.

867 64. Montefiori, L. et al. Extremely long-range chromatin loops link topolotical domains

868 to facilitate a diverse antibody repertoire. Cell Rep. 14, 896-906 (2016).

869 65. Janssen, E. et al. A DOCK8-WIP-WASp complex links T cell receptors to the actin

870 cytoskeleton. J. Clin. Invest. 126, 3837-3851 (2016).

871 66. Hashimoto, A. \& T. Saito, T. Dynamic regulation of TCR-microclusters and the

872 microsynapse for T cell activation. Front. Immunol. 7, article 255 (2016).

873 67. Ham, H., Huynh, W., Schoon, R.A., Vale, R.D. \& Billadeau, D.D. HkRP3 is a

874 microbubule-binding protein regulating lytic granule clustering and NK cell killing. J.

875 Immunol. 194, 3984-3996 (2015).

876 68. Ji, Y., Resch, W., Corbett, E., Yamane, A., Casellas, R. \& Schatz, D.G. The in vivo

877 pattern of binding of RAG1 and RAG2 to antigen receptor loci. Cell 141, 419-431

878 (2010). 
69. Chen, S. et al. A lamina-associated domain border governs nuclear lamina

880 interactions, transcription, and recombination of the Tcrb locus. Cell Res. 25, 1729-40

881 (2018).

882 70. Zacarias-Cabeza, J. et al. Transcription-dependent generation of a specialized

883 chromatin structure at the TCR $\beta$ locus. J. Immunol. 194, 3432-3443 (2015).

884 71. Villey, I., Caillol, D., Selz, F., Ferrier, P. \& de Villartay, J-P. 1996. Defect in

885 rearrangement of the most 5' TCR-J $\alpha$ following targeted deletion of T early $\alpha$ (TEA):

886 implications for TCR $\alpha$ locus accessibility. Immunity 5, 331-342 (1996).

887 72. Abarrategui, I. \& Krangel, M.S. Noncoding transcription controls downstream

888 promoters to regulate T-cell receptor $\alpha$ recombination. EMBO J. 26, 4380-4390 (2007).

889 73. Carico, Z.M., Choudhury, K.R., Zhang, B., Zhuang, Y. \& Krangel, M.S. Tcrd

890 rearrangement redirects a processive TCRA recombination program to expand the Tcr $\alpha$

891 repertoire. Cell Rep. 19, 2157-2173 (2017).

892 74. Andrews, B.S. et al. Spontaneous murine lupus-like syndromes. Clinical and

893 immunopathological manifestations in several strains. J. Exp. Med. 148, 1198-1215

894 (1978).

895 75. Dao, L.T.M. \& Spicuglia, S. Transcriptional regulation by promoters with enhancer

896 function. Transcription 5, 307-314 (2018). 
897 76. Dao, L.T.M. et al. Genome-wide characterization of mammalian promoters with

898 distal enhancer functions. Nat. Genet. 49, 1073-1081 (2017).

899 77. Crawford, A. et al. Molecular and transcriptional basis of CD4 ${ }^{+} \mathrm{T}$ cell dysfunction

900 during chronic infection. Immunity 40, 289-302 (2014).

901 78. Vella, L.A., Herati, R.S. \& Wherry, E.J. CD4 ${ }^{+}$T cell differentiation in chronic viral 902 infections: the Tfh perspective. Trends Mol. Med. 23, 1072-1087 (2017).

903 79. Cisse, B. et al. Transcription factor E2-2 is an essential and specific regulator of 904 plasmacytoid dendritic cell development. Cell 135, 37-48 (2008).

905 80. Sisirak, V. et al. Genetic evidence for the role of plasmacytoid dendritic cells in 906 systemic lupus erythematosus. J. Exp. Med. 211, 1969-1976 (2014).

907 81. Keles, S. et al. Plasmacytoid dendritic cell depletion in DOCK8 deficiency: rescue 908 of severe herpetic infections with IFN- $\alpha 2 b$ therapy. J. Allergy Clin. Immunol. 133, $909 \quad 1753-1755$ (2014).

910 82. Zinkernagel, R.M. Immunology taught by viruses. Science 271, 173-178 (1996).

911 83. Higdon, L.E., Deets, K.A., Friesen, T.J., Sze, K-Y. \& Fink, P.J. Receptor revision in 912 CD4 T cells is influenced by follicular helper T cell formation and germinal center 913 interactions. Pros NAS 111:5652-5657 (2014). 
914 84. St. Rose, M-C. et al. The E3 ubiquitin ligase Cbl-b regulates expansion but not

915 functional activity of self-reactive CD4 T cells. J. Immunol. 183, 4975-83 (2009).

916 85. Olsen, N.J., Choi, M.Y. \& Fritzler, M.J. Emerging technologies in autoantibody

917 testing for rheumatic diseases. Arthritis Res. Ther. 19:172 (2017).

918 86. Yaniv, G. et al. A volcanic explosion of autoantibodies in systemic lupus

919 erythematosus: a diversity of 180 different antibodies found in SLE patients.

920 Autoimmunity Rev. 14:75-79 (2015).

921 87. Huang, C.Y., Golub, R., Wu, G.E. \& Kanagawa, O. Superantigen-induced TCR $\alpha$ locus

922 secondary rearrangement: role in tolerance induction. J Immunol 168, 3259-3265 (2002).

923 88. Kitaura, K., Shini, T., Matsutani, T. \& Suzuki, R. A new high-throughput sequencing

924 method for determining diversity and similarity of T cell receptor (TCR) and repertoires

925 and identifying potential new invariant TCR chains. BMC Immunol. 17:38 (2016).

926 89. Kitaura, K., Yamashita, H., Ayabe, H., Shini, T., Matsutani, T. \& Suzuki, R.

927 Different somatic hypermutation levels among antibody subclasses sequencing-based

928 antibody repertoire analysis. Front. Immunol. 8:389 (2017).

929 90. Bolstad, B.M., Irrizary, R.A., Astrand, M. \& Speed, T.P. A comparison of 930 normalization methods for high density oligonucleotide array data based on variance and 931 bias. Bioinformatics 19, 185-93 (2003). 
932 91. Gentleman, R.C. et al. Bioconductor: open software development for computational 933 biology and bioinformatics. Genome Biol. 5(19), R80 (2004).

934 92. Quackenbush, J. Microarray data normalization and transformation. Nat Genet 935 32:Suppl., 496-501 (2002).

936 93. Li, Q.Z. et al. Protein array autoantibody profiles for insights into systemic lupus 937 erythematosus and incomplete lupus syndromes. Clin. Exp. Immunol. 147:60-70 (2006). 938 
$940 \quad$ Fig. 1

941 a, Identification of DOCK8 as a marker of aiCD4 T cells.

942 Membrane and cytosolic fractions of either whole T cells (Lanes 1 and 5), CD45RB ${ }^{\text {hi }}$

943 CD122 ${ }^{\text {hi }}$ CD4 T cells (Lanes 2 and 6), CD45RB ${ }^{\text {lo }}$ CD122 ${ }^{\text {lo }}$ PD-1- CD4 T cells (Lanes 3

944 and 7) or $\mathrm{CD}_{45 \mathrm{RB}^{\text {lo }}} \mathrm{CD} 122^{\text {lo }} \mathrm{PD}-1^{+} \mathrm{CD} 4 \mathrm{~T}$ cells (Lanes 4 and 8) from 12x OVA-

945 immunized BALB/c mice, were subjected to $10 \%$ polyacrylamide gel electrophoresis,

946 transferred to Immobilon-P membrane, and stained with anti-DOCK8 Ab.

947 b, Expansion of DOCK $8^{+}$CD4 T cells after repeated immunization with OVA without an 948 adjuvant.

949 Flow cytometry analyses of $\mathrm{DOCK}^{+} \mathrm{CD} 4 \mathrm{~T}$ cell from splenic CD4 T cells of BALB/c 950 mice after repeated 12x stimulation with PBS, 6x with OVA or 12x with OVA.

951 c, Transferred DOCK $8^{+}$CD4 T cells induced autoantibodies in the recipents.

952 Rheumatoid factor (RF), anti-Sm Ab and anti-dsDNA Ab were quantified in the sera of $953 \mathrm{BALB} / \mathrm{c}$ mice that had been pre-immunized 8x with OVA, depleted of CD4 T cells by 954 anti-CD4 Ab and then inoculated with DOCK8 ${ }^{-}$CD4 $\mathrm{T}$ cells or DOCK8 ${ }^{+}$CD4 $\mathrm{T}$ cells 955 from 12x OVA-immunized BALB/c mice. The control group was BALB/c mice pre956 immunized 8x with OVA, CD4 T cell-depleted by anti-CD4 Ab, and inoculate with CD4 
957 T cells from 12x PBS-immunized BALB/c mice. Anti-dsDNA Ab and anti-Sm Ab titers

958 were represented by arbitrary unit (AU). Statistical assessment was by Student's t-test.

959 d, Glomerulonephritis in the BALB/c mice that had been pre-immunized 8x with OVA, 960 depleted of CD4 T cells by anti-CD4 Ab and inoculated with DOCK8- CD4 T cells or

961 DOCK8 ${ }^{+}$CD4 T cells from 12x OVA-immunized BALB/c mice.

962 Control group was the BALB/c mice that had been pre-immunized 8x with OVA, depleted

963 of CD4 $\mathrm{T}$ cells by anti-CD4 Ab, and inoculated with CD4 T cells from 12x PBS-

964 immunized BALB/c mice. Glomerular lesions in mice were classified according to human

965 WHO classification (26) as follows; class I, normal glomeruli; class II, purely mesangial

966 disease; class III, focal proliferative glomerulonephritis; class IV, diffuse proliferative

967 glomerulonephritis; and class V, membraneous glomerulonephritis. Statistical assessment

968 was by Student's t-test. ${ }^{*} \mathrm{p}<0.05,{ }^{*} \mathrm{p}<<0.001$.

969 e, Skin lesion.

970 A: Moderate dermatitis with dermal fibrosis, B: liquefaction degeneration (arrow) in the

971 basal cells of epidermis, and $\mathbf{C}$ : panniculitis in the deep area of the dermis of mice pre-

972 treated 8x with OVA, depleted of CD4 T cells and inoculated with DOCK $8{ }^{+} \mathrm{T}$ cells from

973 12x OVA-immunized mice. D: Discoid lupus-like advanced dermatitis observed in mice

974 immunized $12 \mathrm{x}$ with OVA. E: Healed dermatitis with some fibrosis in $12 \mathrm{x}$ OVA- 
975 immunized mice treated with anti-DOCK8 Ab 24 hours each before the 6x, 8x, 10x and 976 12x OVA immunizations with OVA. H \& E stain. (bar $=30 \mu \mathrm{m}$; original magnification A,B, $977 \quad \mathrm{x} 400, \mathrm{C}, \mathrm{x} 300, \mathrm{D}, \mathrm{E}, \mathrm{x} 100) .{ }^{*} \mathrm{p}<0.05,{ }^{* *} \mathrm{p}<0.001$

978 f, Summary of lesions other than kidney in BALB/c mice 8x pre-immunized with OVA, 979 CD4 T cell-depleted and inoculated with DOCK8 ${ }^{-}$CD4 T cells or DOCK8 ${ }^{+}$CD4 T cells 980 from 12x OVA-immunized BALB/c mice. Also shown were results from anti-DOCK8 Ab 981 treatment of 12x OVA-immunized mice: Mice received $100 \mu \mathrm{g}$ anti-DOCK8 Ab $24 \mathrm{hr}$ 982 each before the $6 x, 8 x, 10 x$ and $12 x$ OVA immunizations with OVA. *Statistical analysis 983 was by Fisher's exact test.

984 g, Lesion other than kidney or skin including A: lung interstitial pneumonitis, B: 985 interstitial pneumonitis accompanied by angiitis, C: liver pericholangitis, D: Onion-skin 986 lesion with amyloid deposition classical to lupus in the spleen, and F: thyroiditis, 987 accompanied by giant cells, in the BALB/c mice $8 \mathrm{x}$ pre-immunized with OVA, CD4 T 988 cell-depleted, and then inoculated with DOCK $8^{+} \mathrm{CD} 4 \mathrm{~T}$ cells from $12 \mathrm{x}$ OVA-immunized 989 BALB/c mice. E: Classical onion-skin-like lesion with amyloid deposits in the spleen, 990 and G: perineuritis observed in the dermis of the BALB/c mice immunized $12 \mathrm{x}$ with OVA. 991 H \& E stain. (bar=30 $\mu$ m; original magnification x200).

$992 \quad$ Fig. 2 
993 Identification of DOCK $8{ }^{+} \mathrm{CD} 4 \mathrm{~T}$ cells as long-lived T follicular helper T cells located at 994 splenic red pulp, which were increased in the peripheral blood of patients with active SLE.

995 a, A, Morphology of DOCK $8^{+}$CD4 T cell observed by immunoelectron microscopy, 996 stained with rabbit anti-DOCK8 Ab and Au-tagged ant-rabbit IgG Ab. (bar=1 $\mu \mathrm{m}$;

997 original magnification x12,000). B; C, Nuclear membrane portion of DOCK8 ${ }^{+}$CD4 T 998 cell, stained likewise. (bar=1 $\mu \mathrm{m}$; original magnification x18,000; x24,000).

999 b, Surface markers of splenic DOCK $8^{+}$CD4 T cells.

1000 Flow cytometry for ICOS, CXCR5, and PD-1 expression in splenic DOCK8 ${ }^{+}$CD4 T 1001 cells taken 9 days after the final immunization of BALB/c mice immunized 12x with 1002 PBS versus OVA (Left Upper panel). Flow cytometry analysis of ICOS, CXCR5, PD-1, 1003 GATA3, ROR $\gamma$ t, T-bet, Bc16, Ly6C, IFA1, FR4, and GL7 expression in splenic DOCK81004 CD4 T cells and DOCK8 ${ }^{+}$CD4 T cells isolated from 12x OVA-immunized BALB/c 1005 mice. c, Cytokines released in culture supernatants of $1 \times 10^{6} / \mathrm{ml} \mathrm{DOCK} 8^{+}$or DOCK8 ${ }^{-}$CD4 T 1007 cells following incubation with $2 \mu \mathrm{g} / \mathrm{ml}$ anti-CD3 and $5 \mu \mathrm{g} / \mathrm{ml}$ anti-CD28 $\mathrm{Ab}$ at $37^{\circ} \mathrm{C}$ for $100824 \mathrm{hr} .{ }^{*} \mathrm{p}<0.05,{ }^{*} \mathrm{p}<<0.01, * * * \mathrm{p}<0.005, * * * * \mathrm{p}<0.001$. d, $\mathrm{DOCK} 8^{+} \mathrm{CD} 4 \mathrm{~T}$ cells in the spleen of autopsied SLE patient who died before therapy.

1010 Tissues were fixed in 10\% formalin, deparaffinized by graded xylene and graded alcohol 
1011 sequentially, and serially treated with biotinylated anti-DOCK8 monoclonal Ab, alkaline 1012 phosphatase avidin D and anti-rabbit Novolink, followed by reaction with Fast Red and 1013 Histogreen (Red). CD4 T cells were stained with rabbit anti-IFN $\gamma \mathrm{Ab}$ and anti-rabbit IgG $1014 \mathrm{Ab}$ (Blue) serially. S: red pulp sinus. A; central artery. P: penicillar artery. (bar=100 $\mu \mathrm{m}$; 1015 original magnification x100). Inset; Magnified $\mathrm{DOCK}^{+} \mathrm{CD} 4 \mathrm{~T}$ cells (Arrows). 1016 (bar=20 $\mu \mathrm{m}$; original magnification $\mathrm{x} 400)$.

1017 e, Circulating DOCK $8^{+}$CD4 T cells in the peripheral blood of patients with SLE and its 1018 relationship to the SLE disease activity index (SLEDAI). Data of control patients were

1019 depicted as; $\square$ rheumatoid arthritis, $\boldsymbol{\Delta}$ mixed connective tissue disease, $\triangle$ 1020 polymyositis, systemic sclerosis, $\square$ microscopic polyangiitis. Also shown 1021 were quantification of interferon (IFN) in sera of the same patients with SLE measured 1022 by ELISA.

\section{$1023 \quad$ Fig. 3}

a. Expression of V(D)J recombinase complex and related molecules in splenic CD4 T

1025 cells from 12x PBS-immunized BALB/c mice, and in DOCK8 ${ }^{-}$CD4 T cells and 1026 DOCK $8^{+}$CD4 T cells from 12x OVA-immunized BALB/c mice. Two mice were 1027 analyzed for each group. 
b, Western blot analysis of TCR signal transduction molecules in splenic CD4 T cells

1029 from 12x PBS-immunized BALB/c mice, and in DOCK8- CD4 T cells and DOCK8 ${ }^{+}$

1030 CD4 T cells from 12x OVA-immunized BALB/c mice. Two mice were analyzed for

1031 each group.GAPDH, control house keeping glyceraldehyde 3-phosphate dehydrogenase

1032 gene.

1033

c, Heatmap visualization of TCR usage of a combination of TRV and TRJ genes in the

1034 splenic DOCK8- CD4 T cells and DOCK $8^{+}$CD4 T cells from $12 x$ OVA-immunized

1035 mice. Three mice were analyzed for each group.

1036 d, Autoantibody microarray study. Autoantibodies produced in BALB/c mice pre-

1037

immunized 8x with OVA, depleted of CD4 T cells and inoculated with DOCK8- CD4 T

cells or DOCK $8^{+}$CD4 T cells from 12x OVA-immunized BALB/c mice. Control was

1039 autoantibodies produced in BALB/c mice pre-immunized 8x with OVA, depleted of

1040 CD4 T cells and inoculated with CD4 T cells from 12x PBS-immunized BALB/c mice.

1041 Two mice were analyzed for each group.

1042 e, A, Western blot analysis of DOCK 8 and transcription factors in splenic CD4 T cells

1043 from $12 \mathrm{x}$ PBS-immunized BALB/c mice, and in DOCK8 ${ }^{-}$CD4 T cells and DOCK8 ${ }^{+}$

1044 CD4 T cells from 12x OVA-immunized BALB/c mice. Three mice were analyzed for

1045 each group. 
1046 B, Results of gene expression microarray analysis, abstract from Supplementary Table

1047 1. Ratio of mRNA expression of splenic DOCK $8^{+}$CD4 T cells from $12 x$ OVA-

1048 immunized BALB/c mice in comparison to splenic DOCK8- CD4 T cells from $12 \mathrm{x}$

1049 OVA-immunized mice, given as a $\log _{10}$ scale, wherein $2,3,4,5$ and 6 indicated $\times 10^{2}$,

$1050 \times 10^{3}, \times 10^{4}, \times 10^{5}$, and $\times 10^{6}$, respectively.

\section{$1051 \quad$ Fig. 4.}

1052 a, The effect of anti-DOCK8 mAb treatment on autoantibody generation. Autoantibodies, rheumatoid factor (RF), anti-Sm Ab and anti-dsDNA Ab, were analyzed in the sera of $12 \mathrm{x}$

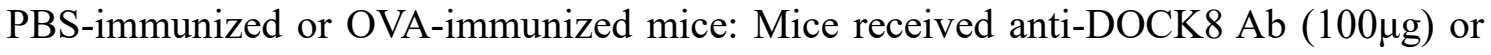
control rabbit IgG $(100 \mu \mathrm{g}) 24 \mathrm{hr}$ each before the 6x, 8x, 10x and 12x OVA immunizations with OVA. Anti-Sm Ab and anti-dsDNA Ab titers were represented by arbitrary unit (AU).

*Statistical analysis was by Student's t-test; $*_{\mathrm{p}}<0.05, \quad * * \mathrm{p}<0.01, \quad * * * \mathrm{p}<0.005$, $* * * * \mathrm{p}<0.001$.

b, The results of anti-DOCK $8 \mathrm{mAb}$ treatment on renal disease.

1060 Upper: Proteinuria, assessed $9 \mathrm{~d}$ after the final immunization and graded with a score of

10610 (<30 mg/dl); 1 (30-99 mg/dl); 2 (100-299 mg/dl); or $3(300-999 \mathrm{mg} / \mathrm{dl})$.

1062 Lower: Kidney lesions of BALB/c mice immunized 12x with either PBS or OVA, and treated either with anti-DOCK8 Ab $(100 \mu \mathrm{g})$ or control rabbit IgG $(100 \mu \mathrm{g}) 24 \mathrm{hr}$ each 
1064 before the 6x, 8x, 10x and 12x OVA immunizations with OVA. Mouse glomerular lesions

1065 were classified according to human WHO classification (26) as follows; class I, normal

1066 glomeruli; class II, purely mesangial disease; class III, focal proliferative

1067 glomerulonephritis; class IV, diffuse proliferative glomerulonephritis; and class V,

1068 membraneous glomerulonephritis. Statistical assessment was by Student's t-test; * $\mathrm{p}<0.05$,

$1069 * * \mathrm{p}<0.005, * * * \mathrm{p}<0.001$

1070 c, Results of anti-DOCK8 mAb treatment on (NZBxNZW) F1 female mice.

1071 Autoantibodies, anti-dsDNA Ab, anti-Sm Ab and rheumatoid factor (RF), and proteinuria

1072 of (NZBxNZW) F1 female mice, treated either with anti-DOCK8 Ab (100 $\mu \mathrm{g})$ or control

1073 rabbit $\operatorname{IgG}(100 \mu \mathrm{g})$ every week from 15 weeks until 24 weeks (arrow). Statistical

1074 assessment performed by Student's t-test; ${ }^{*} \mathrm{p}<0.05,{ }^{*} \mathrm{p}<0.01,{ }^{* * *} \mathrm{p}<0.005,{ }^{* * * *} \mathrm{p}<0.001$ 


\section{Extended Data Table 1}

1077 Diversity score calculation. Percentage of sequence reads with TRAV, TRAJ, TRBV and 1078 TRBJ genes among total sequence reads were calculated. To estimate TCR diversity in 1079 deep sequencing data, diversity indices, Shannon-Weaver index H' and inverted 1080 Simpson index $1 / \lambda$, were used, with unique read and copy number used for species and 1081 individuals in the equations $(47,48)$. Two mice were analyzed for each group.

\section{Extended Data Table 2.} TCR repertoires uniquely expressed in $\mathrm{DOCK} 8^{+} \mathrm{CD} 4^{+} \mathrm{T}$ cells. The TCR repertoires 1084 uniquely expressed in $\mathrm{DOCK} 8^{+} \mathrm{CD}^{+} \mathrm{T}$ cells from $12 \mathrm{x}$ OVA-immunized BALB/c mice, but not in DOCK8 ${ }^{-} \mathrm{CD}^{+} \mathrm{T}$ cells from $12 \mathrm{x}$ OVA-immunized BALB/c mice or $\mathrm{CD} 4^{+} \mathrm{T}$

1086 cells from 12x PBS-stimulated mice. Each 2 mice were compared. Two mice were 1087 analyzed for each group.

\section{Extended Data Fig. 1}

1089 To isolate aiCD4 $\mathrm{T}$ cells, SLE was induced in the BALB/c mice by $12 \mathrm{x}$ repeated 1090 intraperitoneal (i.p.) immunization with OVA without adjuvants, and various subsets of 1091 splenic CD4 T cells were taken and transferred to naïve recipient mice. For each subset 1092 we assessed the generation of rheumatoid factor (RF) and anti-dsDNAAb in the recipient 1093 mice. Rheumatoid factor (RF) and anti-dsDNA antibody (anti-dsDNA Ab) were measured 1094 in naïve recipient BALB/c female mice 2 weeks after the transfer of either CD4 T cells 
1095 from 12x PBS-immunized BALB/c mice, or CD45RB ${ }^{\text {lo }}$ CD122 ${ }^{\text {lo }}$ PD-1 ${ }^{-}$CD4 T cells or $1096 \mathrm{CD}_{5 \mathrm{RB}}{ }^{\text {lo }} \mathrm{CD} 122^{\text {lo }} \mathrm{PD}-1^{+} \mathrm{CD} 4 \mathrm{~T}$ cells from $12 \mathrm{x}$ OVA-immunized BALB/c mice. 1097 Measurement was by ELISA. Anti-dsDNA Ab titers were represented by arbitrary unit 1098 (AU). Statistical assessment performed by Student's t-test; * $\mathrm{p}<0.05$.

\section{Extended Data Fig. 2.}

1100 Induction of autoantibodies and renal disease by the transfer of DOCK $8^{+} \mathrm{CD} 4 \mathrm{~T}$ cells in 1101 naive recipient mice.

1102 a, Autoantibodies, rheumatoid factor (RF) and anti-dsDNA Ab, measured in naïve 1103 recipient mice 2 weeks after the transfer of either CD4 T cells from 12x PBS-immunized 1104 mice, or DOCK8- CD4 T cells or DOCK8 ${ }^{+}$CD4 T cells from 12x OVA-immunized mice.

1105 Anti-dsDNA Ab titers were represented by arbitrary unit (AU). Statistical assessment 1106 performed by Student's t-test; ${ }^{*} \mathrm{p}<0.05, * * \mathrm{p}<0.01, * * * \mathrm{p}<0.005$.

1107 b, Renal disease. Left panel, Proteinuria observed in BALB/c mice that had been 1108 immunized $x 8$ with OVA, depleted of CD4 T cells and inoculated either splenic DOCK8$1109 \mathrm{~T}$ cells or DOCK $8{ }^{+} \mathrm{T}$ cells from 12x OVA-immunized BALB/c mice. Observations were 1110 made 2 weeks after cell transfer. Proteinuria was assessed $9 \mathrm{~d}$ after the final immunization 1111 and graded with a score of $0(<30 \mathrm{mg} / \mathrm{dl}) ; 1(30-99 \mathrm{mg} / \mathrm{dl}) ; 2(100-299 \mathrm{mg} / \mathrm{dl})$; or 3 (300$1112999 \mathrm{mg} / \mathrm{dl}$ ). Middle upper: Wire loop lesion typical of SLE (indicated by arrow), middle 
1113 lower: diffuse proliferative WHO type IV lupus nephritis, right upper: focal segmented

1114 WHO type III nephritis (segmental lesion marked by arrow), and right lower:

1115 glomerulonephritis (WHO type V) with crescent formation observed in BALB/c mice

1116 that had been pre-immunized 8x with OVA, depleted of CD4 T cells and inoculated with

1117 DOCK8 ${ }^{+}$CD4 $\mathrm{T}$ cells from 12x OVA-immunized BALB/c mice. Mouse glomerular

1118 lesions were classified according to human WHO classification (26) as follows; class I,

1119 normal glomeruli; class II, purely mesangial disease; class III, focal proliferative

1120 glomerulonephritis; class IV, diffuse proliferative glomerulonephritis; and class V,

1121 membraneous glomerulonephritis. $\mathrm{H} \&$ E stain. (bar $=30 \mu \mathrm{m}$; original magnification $\mathrm{x} 200$ ).

\section{Extended Data Fig. 3.}

1123 Flow cytometry analysis of CD3, CD4, CD23, CD27, CD43act (activation-associated

1124 glycoform), CD44, CD62L, CD123, CD147, CCR4, CCR7, TLR7, Thy1.2 and TCR $\beta$ of

$1125 \mathrm{DOCK}^{-}$or $\mathrm{DOCK} 8^{+} \mathrm{CD} 4 \mathrm{~T}$ cells taken from BALB/c mice 9 days after $12 \mathrm{x}$

1126 immunization with OVA.

1127 Extended Dada Fig. 4.

1128 a, Flow cytometry analysis of CCR4 and Ly6c, CCR4 and LFA1, and Ly6c and LFA in

$1129 \mathrm{DOCK}^{-}$or $\mathrm{DOCK}^{+} \mathrm{CD} 4 \mathrm{~T}$ cells taken from BALB/c mice 9 days after $12 \mathrm{x}$

1130 immunization with OVA. 
1131 b, Regulatory T cell surface markers. Flow cytometry analysis of DOCK8, CD25,

1132 Foxp3 and CD4 expression in the spleens of BALB/c mice immunized 12x with OVA

1133 (Upper panel). Flow cytometry analysis of CD25, Foxp3 and CD4 in the spleens of

1134 BALB/c mice immunized 12x with OVA compared to those mock-immunized 12x with

1135 PBS.

\section{Extended Data Fig. 5.}

1137 Flow cytometry analysis of B cells in spleen of 12x OVA-immunized versus 12x PBS-

1138 immunized BALB/c mice. Statistical analysis was by Student's t-test; * $p<0.05$.

1139 Extended Data Fig. 6.

1140 Heatmap visualization of the TCRA usage involving a combination of TRAV and

1141 TRAJ genes in splenic DOCK $8^{+}$CD4 T cells versus DOCK8- CD4 T cells from 12x

1142 OVA-immunized BALB/c mice, as well as CD4 T cells from 12x PBS-immunized mice.

\section{Extended Data Fig.7.}

1144 Heatmap visualization of the TCRB usage involving a combination of TRBV and TRBJ

1145 genes in splenic DOCK8 ${ }^{+}$CD4 T cells versus DOCK8 ${ }^{-}$CD4 T cells from 12x OVA-

1146 immunized BALB/c mice, as well as CD4 T cells from 12x PBS-immunized mice.

1147 Extended Dada Fig. 8. 
1148 aiCD4 T cells are generated thru resuscitation from anergy, irrespective of antigen or

1149 genetic background, in the presence of NKT cells.

1150 a, Induction of aiCD4 T cells by repeated OVA immunization in mice with a different

1151 genetic background, C57BL/6.

1152 Generation of autoantibodies, RF and anti-dsDNA Ab, IFN $\gamma^{+} \mathrm{CD} 8^{+} \mathrm{T}$ cells, and

1153 proteinuria in C57BL/6 mice after 12x immunization with OVA. Statistical analysis

1154 performed by Student's t-test; ${ }^{*} \mathrm{p}<0.05, * * * \mathrm{p}<0.005$

$1155 \mathbf{b}, \mathbf{c}$, Induction of aiCD4 T cells by repeated stimulation with SEB in BALB/c mice.

1156 After $2 \mathrm{x}$ stimulation with SEB $(25 \mu \mathrm{g})$, SEB-reactive $\mathrm{V} \beta 8^{+} \mathrm{CD} 4 \mathrm{~T}$ cells were rendered

1157 into anergy; IL-2 production and cell division ceased. Upon further repeated

1158 immunization 8x with SEB, once-anergized CD4 T cells began to secrete IL-2 and

1159 proliferate. This recovered from anergy was accompanied by autoantibody induction.

1160 Cells did not recover from anergy upon 8x stimulation with SEA $(25 \mu \mathrm{g})$, which was

1161 incompatible with TCR V $\beta 8$, but recovered from anergy upon 8x stimulation with SEA

1162 in combination with $\alpha$-galactosyl ceramide $(\alpha \mathrm{GalCer})(25 \mu \mathrm{g})$. The CD4 T cells from

1163 CD1d KO mice also did not recover from anergy. Statistical analysis was by $* \mathrm{p}<0.05$,

$1164 * * \mathrm{p}<0.01$

1165 Extended Data Fig. 9. 
1166 Chromatin-immunoprecipitation sequencing (ChIP-seq) assay and LM-PCR for

1167 chromatin accessibility and V(D)J recombination.

1168 a, Histone acetylation $(\mathrm{AcH} 3)$ and $\mathrm{H} 3 \mathrm{~K} 4$ methylation $(\mathrm{H} 3 \mathrm{~K} 4 \mathrm{me} 3)$ of the TCRA gene of 1169 splenic aiCD4 T cells from 8x SEB-stimulated BALB/c mice. Splenic CD4 T cells of 8x

1170 SEB-stimulated BALB/c mice which produced amply high titers of autoantibodies were 1171 assayed. TEA, TCR $\alpha$ promoter. E $\alpha$, TCR $\alpha$ enhancer.

1172 b, Histone acetylation $(\mathrm{AcH} 3)$ and $\mathrm{H} 3 \mathrm{~K} 4$ methylation $(\mathrm{H} 3 \mathrm{~K} 4 \mathrm{me} 3)$ of the TCRB gene of 1173 splenic aiCD4 T cells from 8x SEB-stimulated BALB/c mice. E $\beta$, TCR $\beta$ enhancer. MyoD

1174 (myoblast determination 1) was used as negative controls.

1175 c, TCR $\alpha$ chain revision in the spleen of mice immunized 8x with SEB was determined by

1176 LM-PCR detection of dsDNA breaks at the RSS flanking the TCRAJ12, and its

1177 confirmation by sequencing.

1178 Extended Data Fig. 10.

1179 a, Expression of IFN signature genes. Results in gene expression microarray analysis,

1180 abstract from Supplementary Table 1. Ratio of mRNA expression of splenic DOCK $8^{+}$

1181 CD4 T cells from 12x OVA-immunized BALB/c mice in comparison to splenic

1182 DOCK8- CD4 T cells from 12x OVA-immunized mice, given as a $\log _{10}$ scale, wherein

$11832,3,4,5$ and 6 indicated $\times 10^{2}, \times 10^{3}, \times 10^{4}, \times 10^{5}$, and $\times 10^{6}$, respectively. 
1184 b, Flow cytometry analysis of plasmacytoid dendritic cell (pDC) markers.

1185 BST2 and SiglecH, BST2 and B220, and BST2 and CD11c in DOCK8 ${ }^{+}$versus

1186 DOCK8- CD4 T cells from BALB/c mice 9 days after $12 \mathrm{x}$ immunization with OVA.

1187

1188 Supplementary Table 1.

1189 Gene expression microarray results. Comparison among splenic DOCK $8{ }^{+}$CD4 T cells of

1190 x12 OVA-immunized BALB/c mice, the splenic DOCK8- CD4 T cells of x12 OVA-

1191 immunized mice, and the CD4 T cells of x12 PBS-immunized mice.

1192 Supplementary Table 2.

1193 Result of next-generation sequencing of TCR genes of splenic DOCK $8^{+}$CD4 T cells of

1194 x12 OVA-immunized BALB/c mice, the splenic DOCK8- CD4 T cells of x12 OVA-

1195 immunized mice, and the CD4 T cells of x12 PBS-immunized mice.

1196 Supplementary Table 3.

1197 Primer and probe sequences used in CHIP assay. 


\section{Figures}
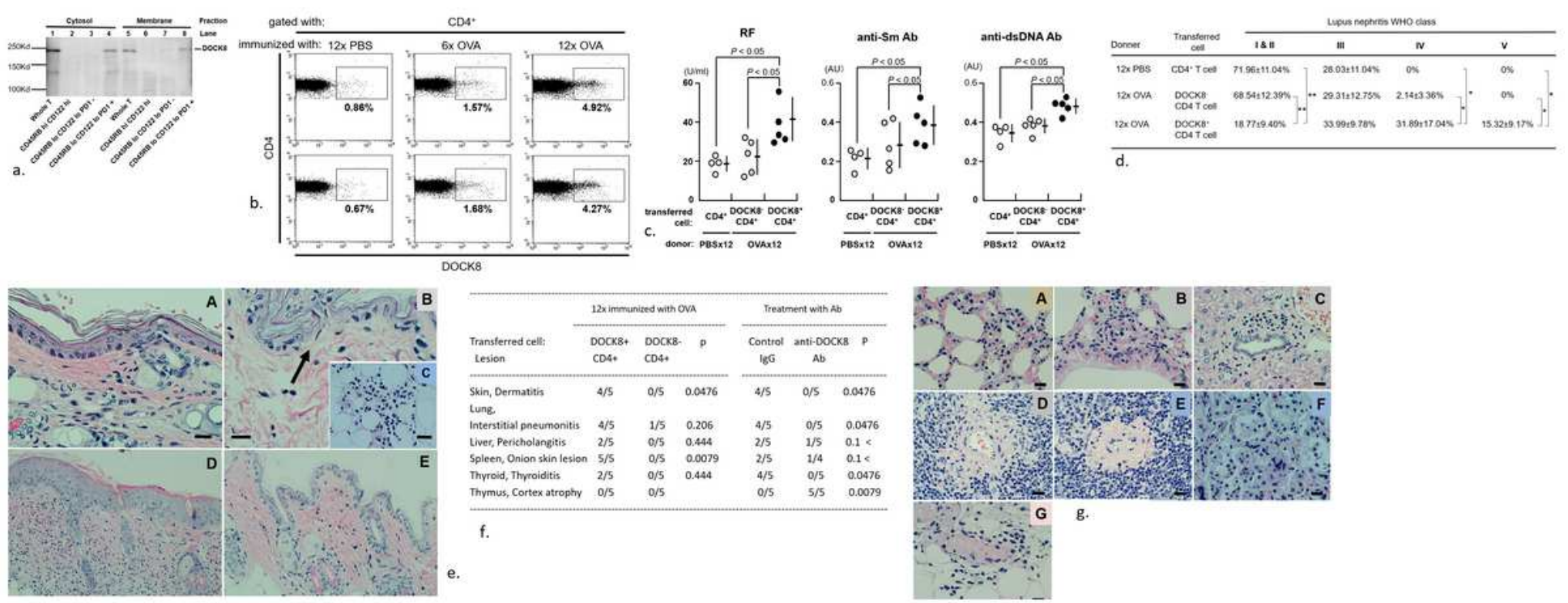

\section{Figure 1}

a, Identification of DOCK8 as a marker of aiCD4 T cells. Membrane and cytosolic fractions of either whole T cells (Lanes 1 and 5), CD45RBhi CD122hi CD4 T cells (Lanes 2 and 6), CD45RBlo CD122lo PD-1- CD4 T cells (Lanes 3 and 7) or CD45RBlo CD122lo PD-1+ CD 4 T cells (Lanes 4 and 8) from 12x OVA-immunized BALB/c mice, were subjected to $10 \%$ polyacrylamide gel electrophoresis, transferred to Immobilon-P membrane, and stained with anti-DOCK8 Ab. b, Expansion of DOCK8+ CD4 T cells after repeated immunization with OVA without an adjuvant Flow cytometry analyses of DOCK8+ CD4 T cell from splenic CD4 T cells of BALB/c mice after repeated $12 x$ stimulation with PBS, $6 x$ with OVA or $12 x$ with OVA. $c$, Transferred DOCK8+ CD 4 T cells induced autoantibodies in the recipents. Rheumatoid factor (RF), anti$\mathrm{Sm} A b$ and anti-dsDNA Ab were quantified in the sera of BALB/c mice that had been pre-immunized $8 \mathrm{x}$ with OVA, depleted of CD4 T cells by anti-CD4 Ab and then inoculated with DOCK8- CD4 T cells or DOCK8+ CD4 T cells from 12x OVA-immunized BALB/c mice. The control group was BALB/c mice preimmunized $8 x$ with OVA, CD 4 T cell-depleted by anti-CD $4 \mathrm{Ab}$, and inoculate with $\mathrm{CD} 4 \mathrm{~T}$ cells from $12 \mathrm{x}$ PBS-immunized BALB/c mice. Anti-dsDNA Ab and anti-Sm Ab titers were represented by arbitrary unit $(A U)$. Statistical assessment was by Student's t-test. $d$, Glomerulonephritis in the BALB/c mice that had been pre-immunized $8 x$ with OVA, depleted of CD4 T cells by anti-CD4 Ab and inoculated with DOCK8CD4 T cells or DOCK8+ CD4 T cells from 12x OVA-immunized BALB/c mice. Control group was the $B A L B / c$ mice that had been pre-immunized $8 x$ with OVA, depleted of CD4 T cells by anti-CD4 Ab, and inoculated with CD4 T cells from 12x PBS-immunized BALB/c mice. Glomerular lesions in mice were classified according to human WHO classification (26) as follows; class I, normal glomeruli; class II, purely mesangial disease; class III, focal proliferative glomerulonephritis; class IV, diffuse proliferative glomerulonephritis; and class V, membraneous glomerulonephritis. Statistical assessment was by Student's t-test. ${ }^{*} \mathrm{p}<0.05,{ }^{*} \mathrm{p}<0.001$. e, Skin lesion. A: Moderate dermatitis with dermal fibrosis, $\mathrm{B}$ : liquefaction degeneration (arrow) in the basal cells of epidermis, and C: panniculitis in the deep area of 
the dermis of mice pre-treated $8 x$ with OVA, depleted of CD4 T cells and inoculated with DOCK8+ T cells from 12x OVA-immunized mice. D: Discoid lupus-like advanced dermatitis observed in mice immunized $12 x$ with OVA. E: Healed dermatitis with some fibrosis in 12x OVA-immunized mice treated with antiDOCK8 Ab 24 hours each before the 6x, 8x, 10x and 12x OVA immunizations with OVA. H \& E stain. (bar $=30 \mu m$; original magnification $A, B, x 400, C, x 300, D, E, x 100$ ). ${ }^{*} p<0.05$, $* * p<0.001 \mathrm{f}$, Summary of lesions other than kidney in BALB/c mice 8x pre-immunized with OVA, CD4 T cell-depleted and inoculated with DOCK8- CD 4 T cells or DOCK8+ CD4 T cells from 12x OVA-immunized BALB/c mice. Also shown were results from anti-DOCK $8 \mathrm{Ab}$ treatment of 12x OVA-immunized mice: Mice received $100 \mathrm{~g}$ antiDOCK8 Ab 24 hr each before the 6x, 8x, 10x and 12x OVA immunizations with OVA. *Statistical analysis was by Fisher's exact test. $g$, Lesion other than kidney or skin including A: lung interstitial pneumonitis, B: interstitial pneumonitis accompanied by angiitis, C: liver pericholangitis, D: Onion-skin lesion with amyloid deposition classical to lupus in the spleen, and $\mathrm{F}$ : thyroiditis, accompanied by giant cells, in the BALB/c mice 8x pre-immunized with OVA, CD 4 T cell-depleted, and then inoculated with DOCK8+ CD $4 T$ cells from 12x OVA-immunized BALB/c mice. E: Classical onion-skin-like lesion with amyloid deposits in the spleen, and G: perineuritis observed in the dermis of the BALB/c mice immunized $12 x$ with OVA. H \& $E$ stain. (bar=30 $\mu$ m; original magnification $\times 200)$.
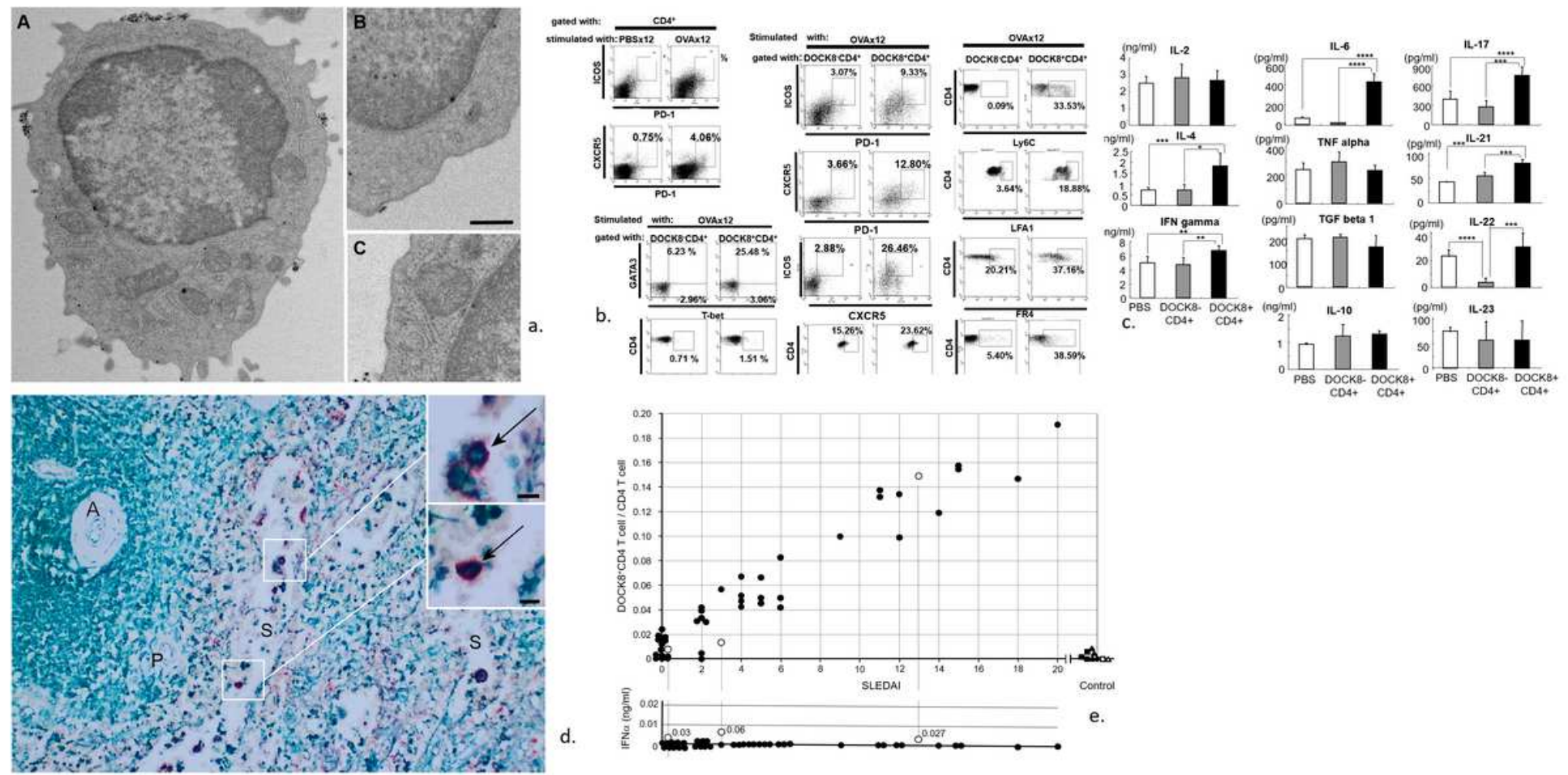

\section{Figure 2}

Identification of DOCK8+ CD4 T cells as long-lived T follicular helper T cells located at splenic red pulp, which were increased in the peripheral blood of patients with active SLE. a, A, Morphology of DOCK8+ CD4 T cell observed by immunoelectron microscopy, stained with rabbit anti-DOCK8 Ab and Au-tagged ant-rabbit IgG Ab. (bar=1 $\mu \mathrm{m}$; original magnification $\times 12,000)$. B; C, Nuclear membrane portion of DOCK8+ CD4 T cell, stained likewise. (bar $=1 \mu \mathrm{m}$; original magnification $x 18,000 ; \times 24,000$ ). $b$, Surface markers of 
splenic DOCK8+ CD4 T cells. Flow cytometry for ICOS, CXCR5, and PD-1 expression in splenic DOCK8+ CD4 $T$ cells taken 9 days after the final immunization of BALB/c mice immunized 12x with PBS versus OVA (Left Upper panel). Flow cytometry analysis of ICOS, CXCR5, PD-1, GATA3, RORyt, T-bet, Bcl6, Ly6C, IFA1, FR4, and GL7 expression in splenic DOCK8- CD4 T cells and DOCK8+ CD4 T cells isolated from 12x OVA-immunized BALB/c mice. c, Cytokines released in culture supernatants of $1 \times 106 / \mathrm{ml}$ DOCK8+ or DOCK8- CD4 T cells following incubation with $2 \mathrm{gg} / \mathrm{ml}$ anti anti-CD3 and $5 \mathrm{gg} / \mathrm{ml}$ anti anti-CD28 $\mathrm{Ab}$ at $37 \llbracket C$ for $24 \mathrm{hr}$. ${ }^{*} p<0.05,{ }^{*} p<0.01,{ }^{* \star *} p<0.005,{ }^{* \star \star *} p<0.001$. d, DOCK8+CD4 T cells in the spleen of autopsied SLE patient who died before therapy. Tissues were fixed in $10 \%$ formalin, deparaffinized by graded xylene and graded alcohol sequentially, and serially treated with biotinylated anti-DOCK8 monoclonal $\mathrm{Ab}$, alkaline phosphatase avidin $\mathrm{D}$ and anti-rabbit Novolink, followed by reaction with Fast Red and Histogreen (Red). CD4 T cells were stained with rabbit anti-IFNY Ab and anti-rabbit IgG Ab (Blue) serially. S: red pulp sinus. A; central artery. P: penicillar artery. (bar $=100 \mu m$; original magnification x100).

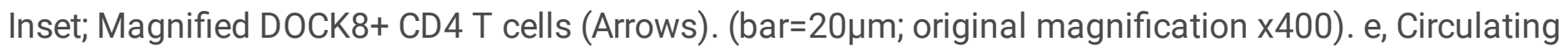
DOCK8+ CD4 T cells in the peripheral blood of patients with SLE and its relationship to the SLE disease activity index (SLEDAI). Data of control patients were depicted as; $\mathbb{\text { Q }}$ rheumatoid arthritis, $\mathbb{Q}$ m mixed

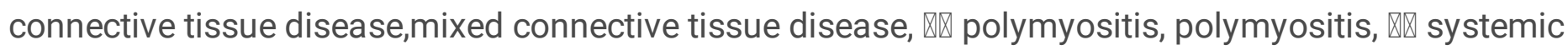
systemic sclerosis, sclerosis, $\mathbb{Q}$ microscopic polyangiitis.microscopic polyangiitis. Also shown were quantification of interferon (IFN) in sera of the same patients with SLE measured by ELISA.

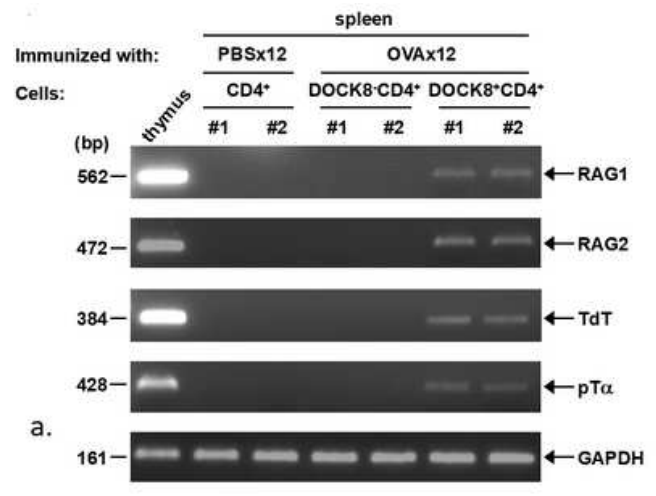

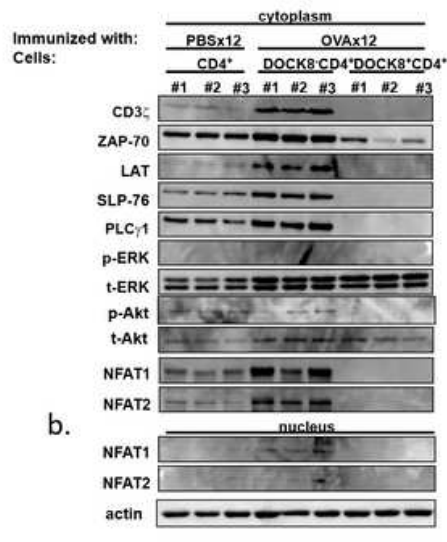
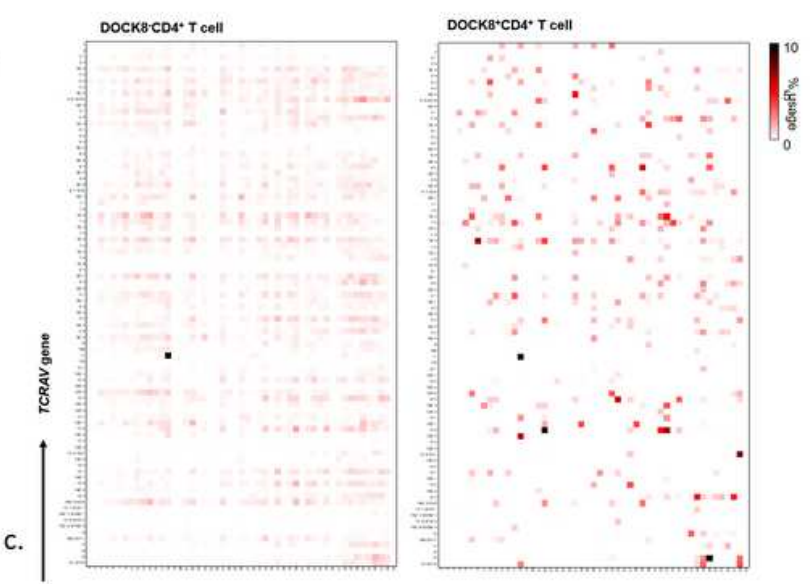
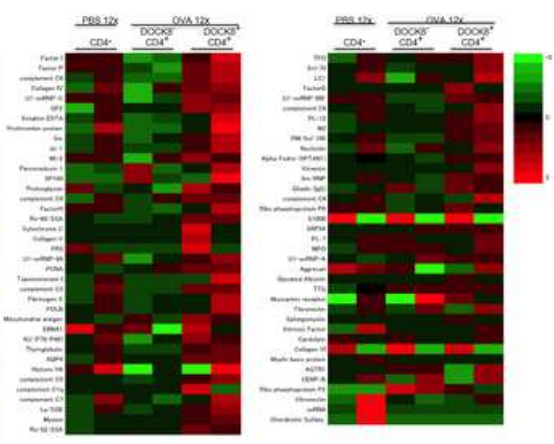

e.
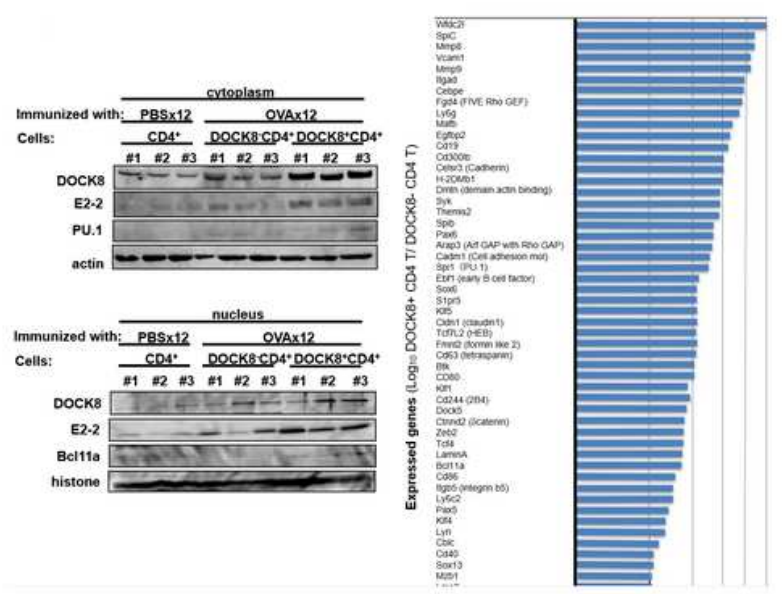

Figure 3 
a. Expression of $\mathrm{V}(\mathrm{D}) \mathrm{J}$ recombinase complex and related molecules in splenic CD4 T cells from 12x PBSimmunized BALB/c mice, and in DOCK8- CD4 T cells and DOCK8+ CD4 T cells from 12x OVA-immunized BALB/c mice. Two mice were analyzed for each group. b, Western blot analysis of TCR signal transduction molecules in splenic CD4 T cells from 12x PBS-immunized BALB/c mice, and in DOCK8CD4 T cells and DOCK8+ CD 4 T cells from 12x OVA-immunized BALB/c mice. Two mice were analyzed for each group.GAPDH, control house keeping glyceraldehyde 3-phosphate dehydrogenase gene. $\mathrm{C}$, Heatmap visualization of TCR usage of a combination of TRV and TRJ genes in the splenic DOCK8- CD4 T cells and DOCK8+ CD4 T cells from 12x OVA-immunized mice. Three mice were analyzed for each group. d, Autoantibody microarray study. Autoantibodies produced in BALB/c mice pre-immunized $8 x$ with OVA, depleted of CD4 T cells and inoculated with DOCK8- CD4 T cells or DOCK8+ CD4 T cells from 12x OVA-immunized BALB/c mice. Control was autoantibodies produced in BALB/c mice pre-immunized 8x with OVA, depleted of CD4 T cells and inoculated with CD4 T cells from 12x PBS-immunized BALB/c mice. Two mice were analyzed for each group. e, A, Western blot analysis of DOCK8 and transcription factors in splenic CD4 T cells from 12x PBS-immunized BALB/c mice, and in DOCK8- CD4 T cells and DOCK8+ CD4 T cells from 12x OVA-immunized BALB/c mice. Three mice were analyzed for each group. $B$, Results of gene expression microarray analysis, abstract from Supplementary Table 1. Ratio of mRNA expression of splenic DOCK8+ CD 4 T cells from 12x OVA-immunized BALB/c mice in comparison to splenic DOCK8- CD4 T cells from 12x OVA-immunized mice, given as a log10 scale, wherein 2, 3, 4, 5 and 6 indicated x102, x103, x104, x105, and x106, respectively.

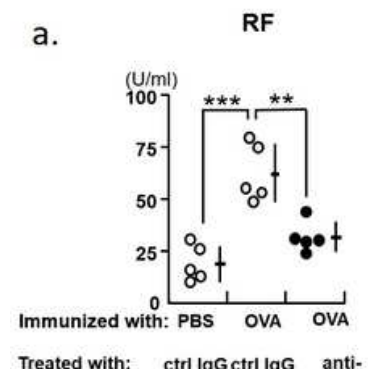

Treated with: ctrl lgG ctrl lgG $\begin{gathered}\text { anti- } \\ \text { DOCK8 Ab }\end{gathered}$
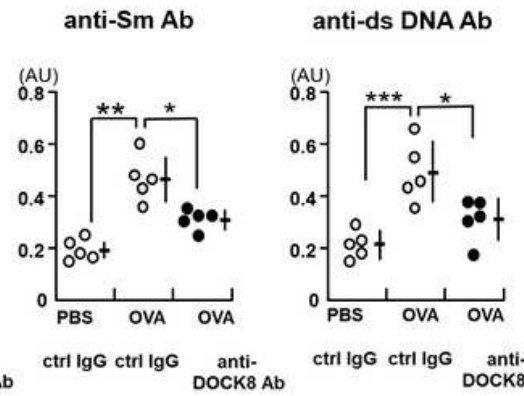

ctrl lgG ctrligG anti-
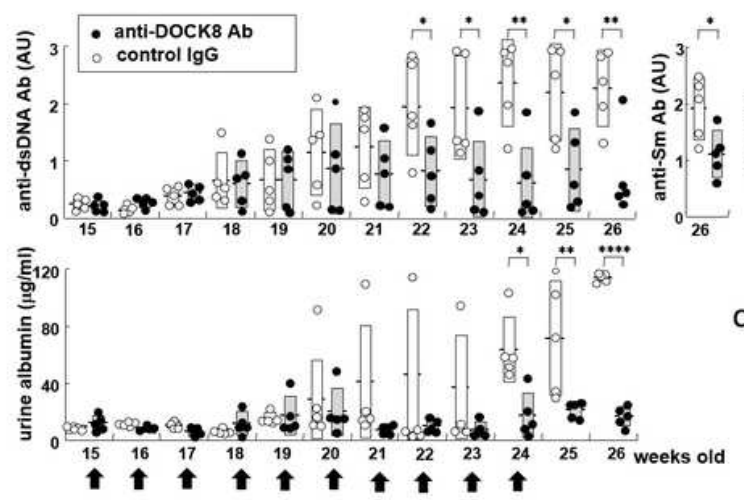

b.
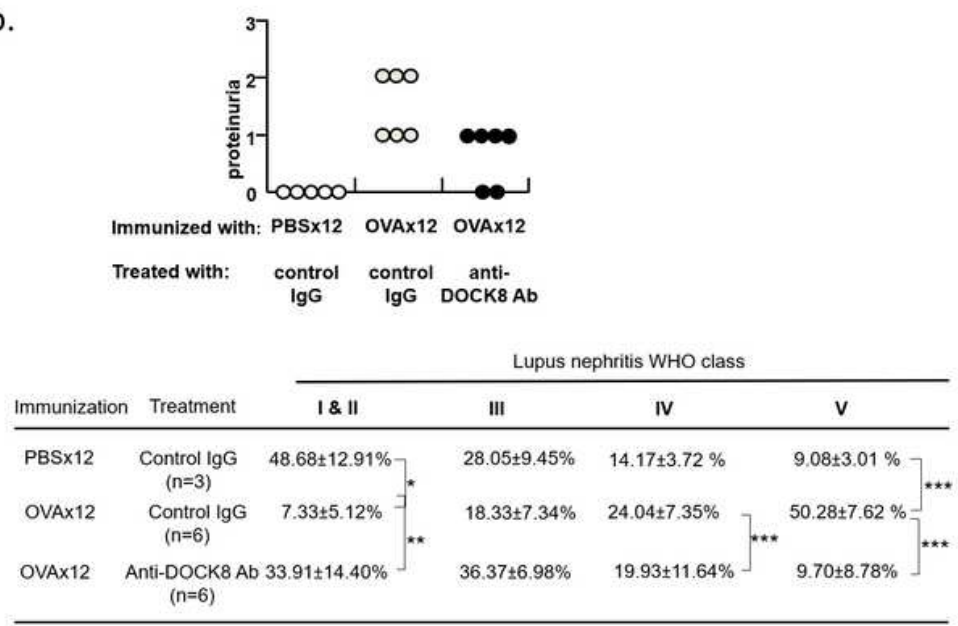

\section{Figure 4}

a, The effect of anti-DOCK8 mAb treatment on autoantibody generation. Autoantibodies, rheumatoid factor (RF), anti-Sm Ab and anti-dsDNA Ab, were analyzed in the sera of 12x PBS-immunized or OVAimmunized mice: Mice received anti-DOCK8 Ab $(100 \mu \mathrm{g})$ or control rabbit lgG $(100 \mu \mathrm{g}) 24 \mathrm{hr}$ each before 
the 6x, 8x, 10x and 12x OVA immunizations with OVA. Anti-Sm Ab and anti-dsDNA Ab titers were represented by arbitrary unit $(A U)$. *Statistical analysis was by Student's t-test; ${ }^{*} p<0.05,{ }^{* \star} p<0.01$, ${ }^{\star * \star} \mathrm{p}<0.005,{ }^{* \star \star \star} \mathrm{p}<0.001$. b. The results of anti-DOCK8 mAb treatment on renal disease. Upper: Proteinuria, assessed $9 \mathrm{~d}$ after the final immunization and graded with a score of $0(<30 \mathrm{mg} / \mathrm{dl}) ; 1(30-99 \mathrm{mg} / \mathrm{dl}) ; 2$ (100-299 mg/dl); or 3 (300-999 mg/dl). Lower: Kidney lesions of BALB/c mice immunized 12x with either PBS or OVA, and treated either with anti-DOCK8 Ab $(100 \mu \mathrm{g})$ or control rabbit lgG $(100 \mu \mathrm{g}) 24 \mathrm{hr}$ each before the $6 x, 8 x, 10 x$ and 12x OVA immunizations with OVA. Mouse glomerular lesions were classified according to human WHO classification (26) as follows; class I, normal glomeruli; class II, purely mesangial disease; class III, focal proliferative glomerulonephritis; class IV, diffuse proliferative glomerulonephritis; and class V, membraneous glomerulonephritis. Statistical assessment was by Student's t-test; ${ }^{*} p<0.05,{ }^{*} p<<0.005,{ }^{\star \star \star} p<0.001$. c, Results of anti-DOCK8 mAb treatment on (NZBxNZW) F1 female mice. Autoantibodies, anti-dsDNA Ab, anti-Sm Ab and rheumatoid factor (RF), and proteinuria of (NZBxNZW) F1 female mice, treated either with anti-DOCK8 Ab (100 एवgg) or control rabbit IgG (100 $\mathrm{QIg}) \mathrm{g}$ ) every week from 15 weeks until 24 weeks (arrow). Statistical assessment performed by Student's t-test; ${ }^{\star} \mathrm{p}<0.05,{ }^{\star \star} \mathrm{p}<0.01,{ }^{\star \star \star} \mathrm{p}<0.005,{ }^{* \star \star \star} \mathrm{p}<0.001$.

\section{Supplementary Files}

This is a list of supplementary files associated with this preprint. Click to download.

- SupplTable1Nature20209.23.MicroarrayDataforDOCK8manuscriptall20170404withlincRNA.xls

- ShiozawaSetal.FIGURES16SupplTable3.Dock8CD4TasaiCD4Tcell.pdf

- PBSCD4mouse1KBT01amousetrareport.xlsx

- PBSCD4mouse1KBT01bmousetrbreport.xlsx

- PBSCD4mouse2KBT02amousetrareport.xlsx

- PBSCD4mouse2KBT02bmousetrbreport.xlsx

- OVADOCK8CD4mouse1KBT03amousetrareport.xlsx

- OVADOCK8CD4mouse1KBT03bmousetrbreport.xlsx

- OVADOCK8CD4mouse2KBT04amousetrareport.xlsx

- OVADOCK8CD4mouse1KBT05amousetrareport.xlsx

- OVADOCK8CD4mouse1KBT05bmousetrbreport.xlsx

- OVADOCK8CD4mouse2KBT06amousetrareport.xlsx

- OVADOCK8CD4mouse2KBT06bmousetrbreport.xlsx

- ShiozawaSetal.FIGURES16ExtData.Dock8CD4TasaiCD4Tcell.pdf

- ShiozawaSetal.FIGURES16Figs.Dock8CD4TasaiCD4Tcell.ppt 